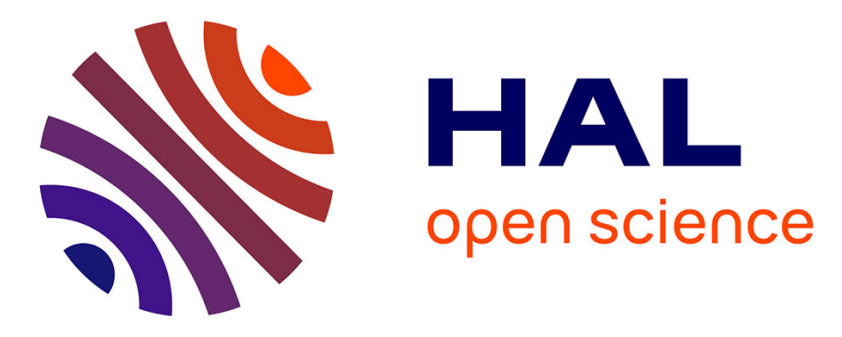

\title{
Lignin-first integrated steam explosion process for green wood adhesive application
}

\author{
Qian He, Isabelle Ziegler-Devin, Laurent Chrusciel, Sebastien Ngwa Obame, \\ Lu Hong, Xiaoning Lu, Nicolas Brosse
}

\section{- To cite this version:}

Qian He, Isabelle Ziegler-Devin, Laurent Chrusciel, Sebastien Ngwa Obame, Lu Hong, et al.. Ligninfirst integrated steam explosion process for green wood adhesive application. ACS Sustainable Chemistry \& Engineering, 2020, 8 (13), pp.5380-5392. 10.1021/acssuschemeng.0c01065 . hal-02542097

\section{HAL Id: hal-02542097 \\ https://hal.univ-lorraine.fr/hal-02542097}

Submitted on 14 Apr 2020

HAL is a multi-disciplinary open access archive for the deposit and dissemination of scientific research documents, whether they are published or not. The documents may come from teaching and research institutions in France or abroad, or from public or private research centers.
L'archive ouverte pluridisciplinaire HAL, est destinée au dépôt et à la diffusion de documents scientifiques de niveau recherche, publiés ou non, émanant des établissements d'enseignement et de recherche français ou étrangers, des laboratoires publics ou privés. 


\section{Lignin-first integrated steam explosion process \\ for green wood adhesive application}

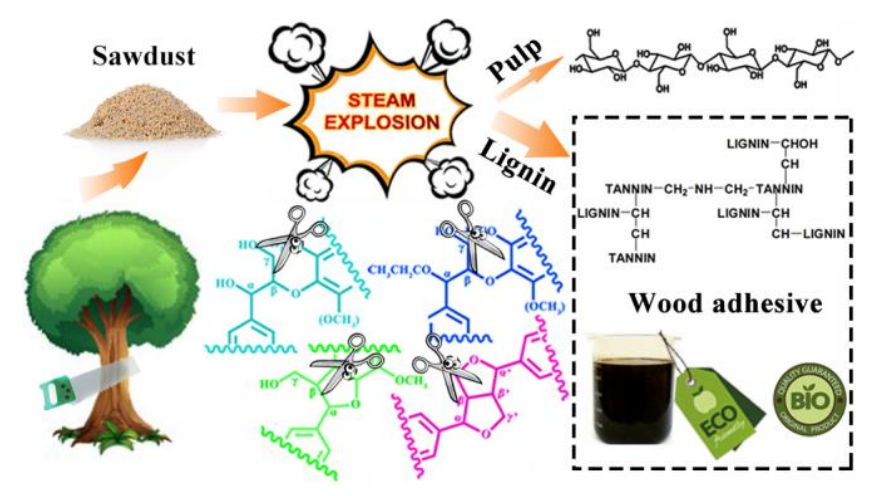

Qian He $^{\text {qø }}$, Isabelle Ziegler-Devin ${ }^{\varnothing}$, Laurent Chrusciel $^{\varnothing}$, Sebastien Ngwa Obame ${ }^{\varnothing}$, Lu Hong ${ }^{\text {II }}$ Xiaoning Lu ${ }^{\text {Il }}$, Nicolas Brosse ${ }^{\emptyset_{*}}$

${ }^{\mathbb{I}}$ College of Materials Science and Engineering, Nanjing Forestry University, People's Republic of China (PRC), 210037, China

${ }^{\varnothing}$ Université de Lorraine, INRAE, LERMAB, F-54000 Nancy, France

*Corresponding author: Nicolas Brosse

Email address: Nicolas.Brosse@univ-lorraine.fr

\section{Abstract:}

Steam explosion (SE) is one of the most advanced pretreatment processes currently used for the production of biofuel from lignocellulose. However, steam explosion lignin is generally recovered as a secondary impure co-product, mainly used for energy production. In this work, beech wood sawdust was first exploded at $180^{\circ} \mathrm{C}$ or $200^{\circ} \mathrm{C}$ during $5 \mathrm{~min}$ after water or dilute acid impregnation. The recovery of lignin from exploded wood was studied using an alkali process at $80^{\circ} \mathrm{C}$ or an ethanol-organosolv process at $200^{\circ} \mathrm{C}$. The impact of the SE parameters and of the delignification step on the lignin structure was examined by size exclusion and ionic chromatography (SEC), ${ }^{31} \mathrm{P}$ and HSQC NMR spectroscopies. The different lignin 
fractions have been evaluated for the production of adhesive without addition of any synthetic resin, composed of $50 \%$ glyoxalated lignin and $50 \%$ tannins. It was demonstrated by thermomechanical analysis (TMA) that the parameters of the process greatly impact the performance of the resulting resin. SE lignin produced from acid SE ( $a$-SE) treatment at $200^{\circ} \mathrm{C}$ followed by an alkaline delignification led to an adhesive formulation displaying a very good performance with $\mathrm{MOE}_{\max } \approx 6000 \mathrm{MPa}$.

Keywords: lignin, steam explosion, wood adhesive 


\section{Introduction}

Lignin is an aromatic polymer composed of p-hydroxyphenyl $(\mathrm{H})$, guaiacyl $(\mathrm{G})$ and syringyl (S) units resulting of a random radical polymerization. The main linkages between the units are $\beta-\mathrm{O}-4, \beta-\beta$ and $\beta-5$ forming a large and complex molecular structure. ${ }^{1}$ Due to its renewable, abundant and environmentally friendly nature, lignin is an increasingly attractive bioresource for use in various applications such as aromatic monomers, carbon fibers, additives in composites. ${ }^{2}$ One of the most advanced and promising applications is lignin-based resins production, lignin being used as a partial substitute for phenolic wood adhesives.. ${ }^{3,4}$ Numerous publications have described the production of phenol-lignin resins or lignin-tannins resins. More recently, environmentally friendly and formadehyde-free wood adhesives composed of tannins-lignin mixture with glyoxal or other non-toxic aldehydes as cross linkers have been reported. ${ }^{5}$ However, due to the poor quality and high variability of industrial lignins as well as their low chemical reactivity, industrial developments in this field are rare. ${ }^{6}$ Unlike kraft and organosolv lignins, which have been extensively studied for adhesive application, exploded wood lignin has received very little attention. $^{7,8,9}$.

Steam explosion treatment (SE) is one of the most useful, efficient and eco-friendly method to pretreat biomass. This technology is under development at commercial scale for bioethanol production. ${ }^{10}$ During SE treatment, the lignocellulosic biomass is subjected to steam under high pressure and high temperature followed by an explosive 
pressure release. ${ }^{11}$ This procedure led to hydrolysis and redistribution of biomass components, increasing the enzymatic digestibility of cellulose and polysaccharides for biofuel production by fermentation. ${ }^{12}$ It is well known that SE has also a strong impact on the lignin polymer increasing its extractability. ${ }^{13}$ The relocation of lignin in form of beads at the surface of the cellulose fibers has observed by several authors. ${ }^{14,}$ ${ }^{15}$ It is known that acidic biomass pre-impregnation prior to SE further improved the degradation extent for hemi-cellulose, the lignin depolymerization through $\beta-\mathrm{O}-4$ scissions and efficiency of SE treatment. ${ }^{16,17,18}$

In the current industrial approaches most of the lignin is not isolated after the steam explosion step but at the end of the whole process after the ethanol recovery. As a result, in contrast with organosolv lignin, SE lignin is generally recovered as an impure and low cost co-product, mainly used for energy production. It has been described in previous works that lignin can be isolated from SE wood using an organic solvent or an alkali solution allowing the recovery of low molecular mass lignin. ${ }^{19}$ The lignin removal just after the SE step can then produce a purer and less degraded lignin stream and in the same time a pulp with a low lignin content. ${ }^{20}$ Sun et al. studied alkali and alkaline-ethanol delignifications of exploded bamboo. ${ }^{21}$ Matsakas et al described a hybrid SE/organosolv treatment in order to combine the efficiency of the SE fragmentation and the organosolv extraction for lignin. ${ }^{22}$ Changes occurring in lignin polymer structure after SE have been studied by several authors and it was demonstrated that alkali or organosolv delignification steps used for SE lignin recovery result in some chemical breakdown of the lignin structure. ${ }^{23,24}$ The 
impact of these extraction conditions on SE lignins has not been fully examined yet. A better knowledge of the SE lignin structure and reactivity toward cross linking agents could then stimulate new developments and utilizations of SE lignin in resin applications.

In this study we examined in detail the structures and the characteristics of lignins extracted from exploded beech wood sawdust using alkaline conditions (AL) at $80^{\circ} \mathrm{C}$ or EtOH/water solution at $200^{\circ} \mathrm{C}(\mathrm{EL})$. Before SE treatment, the wood sawdust was impregnated with water or with $1 \% \mathrm{H}_{2} \mathrm{SO}_{4}$ solution. Two severity factors (SFs) of SE treatment were employed: $180^{\circ} \mathrm{C}, 5 \mathrm{~min}(\mathrm{SF} 1)$ and $200^{\circ} \mathrm{C}, 5 \mathrm{~min}(\mathrm{SF} 2)$. The lignin chemical compositions after SE treatment and delignification process were investigated using HPLC, 2D HSQC NMR, ${ }^{31} \mathrm{P}$ NMR and size exclusion chromatography (SEC). With a view to applications in the field of green resins and formaldehyde-free adhesives, the chemical behavior of SE lignins toward cross linking reactions was evaluated by thermomechanical analysis (TMA).

\section{Materials and methods}

\section{Materials}

Beech sawdusts were selected in this study without any decay (Lorraine, Vosges France). The chemical contents were including klason lignin $=23.98 \pm 1.12(\%, \mathrm{w} / \mathrm{w})$, glucose $=40.73 \pm 1.05(\%, \mathrm{w} / \mathrm{w})$, xylose $=21.55 \pm 0.85(\%, \mathrm{w} / \mathrm{w})$, mannose $=1.44 \pm 0.33$ $(\%, \mathrm{w} / \mathrm{w})$, arabinose $=0.31 \pm 0.15(\%, \mathrm{w} / \mathrm{w})$, galactose $=0.88 \pm 0.11(\%, \mathrm{w} / \mathrm{w})$, galacturonic acid $=0.69 \pm 0.13(\%, \mathrm{w} / \mathrm{w})$ and extractive $=2.6 \pm 0.86(\%, \mathrm{w} / \mathrm{w})$. The 
beech sawdust was sifted with a $2 \mathrm{~mm}$ sieve and then oven-dried at $103^{\circ} \mathrm{C}$ for $24 \mathrm{~h}$. The moisture content was $4.5 \%$ and the density was $0.59 \mathrm{~g} \cdot \mathrm{cm}^{-3}$. Mimosa tannins from Tanzania was provided by S.Michele Mondovi', Italy.

\section{Steam explosion (SE) pre-treatment}

The experiment diagram is shown in Figure 1. Before SE treatment, $100 \mathrm{~g}$ of biomass were impregnated in $1 \% \mathrm{H}_{2} \mathrm{SO}_{4}$ (dilute sulfuric acid, by vol.) or distilled water for 15 $\mathrm{h}$ with the liquid/solid ratio of $10 / 1$ respectively at $25^{\circ} \mathrm{C}$. The water impregnated $(w)$ or acid impregnated ( $a$ ) biomass were filtered and then put into a pressurised reactor under varied steam temperatures of $180^{\circ} \mathrm{C}\left(\mathrm{SF} 1, R_{0,1}=3.05\right)$ or $200^{\circ} \mathrm{C}\left(\mathrm{SF} 2, R_{0,2}=3.64\right)$ for a residence time of $5 \mathrm{~min}$, followed by an explosion with pressure relief. After treatment, the solid phase and liquid phase were separated by filtration. The solid phase was washed and then oven-dried at $103^{\circ} \mathrm{C}$ for $24 \mathrm{~h}$. The severity factor (SF) was calculated by the equation:

$$
R_{0}=\log \left(t \times e^{\frac{T-100}{14.75}}\right)
$$

Where $t(\min )$ was SE treatment duration, $T\left({ }^{\circ} \mathrm{C}\right)$ was SE treatment temperature and $R_{0}$ was the SF for SE treatment. The SE treated biomass were labeled as $w 1, w 2, a 1$ and $a 2$ respectively for different conditions.

\section{Milled wood lignin (MWL) recovery}

Beech sawdust was extensively milled by ball milling rotary (PM100, Retsch, Germany) and sifted with a $0.05 \mathrm{~mm}$ sieve. $100 \mathrm{~g}$ of milled powder were extracted with a Soxhlet extraction apparatus by toluene/ethanol (2/1 by vol.) for six hours. The free extractive powder was then mixed with dioxane/water solution (96/4 by vol.) and 
then stirred in the dark for $24 \mathrm{~h}$ with a liquid/solid ratio of $10 / 1$, followed by the filtration. The procedure was repeated three times. The combined dioxane/water extract was concentrated by rotary evaporation and then lyophilized for $48 \mathrm{~h}$. The lignin extract was dissolved in $5 \mathrm{~mL}$ of acetic acid (90\%) for $1 \mathrm{~h}$ at room temperature and was then added to distilled water $(80 \mathrm{~mL} / \mathrm{g}$ lignin). After several centrifugations, the solid phase was dried for $24 \mathrm{~h}$ at $40^{\circ} \mathrm{C}$ and then it was dissolved in $10 \mathrm{~mL}$ of 1,2-dichloroethane/ethanol mixture (2/1, by vol.). The mixture was then centrifuged to remove the insoluble solid; the liquid phase was added into $200 \mathrm{ml}$ of diethyl ether. After centrifugation, the lignin extract was washed three times by diethyl ether and dried for $48 \mathrm{~h}$ at $40^{\circ} \mathrm{C}$. The MWL yield was $0.85 \%$ (based on initial dry wood).

\section{Ethanol lignin (EL) isolation}

$25 \mathrm{~g}$ of oven-dried SE treated biomass were treated with ethanol/water (7/3, by vol.) in a stirred pressurized reactor (Parr Instrument Company, Moline, 0.6L) for $30 \mathrm{~min}$ at $200^{\circ} \mathrm{C}$ with the liquid/solid ratio of $10 / 1$ (by vol.) to obtain EL fractions with appropriate yield and depolymerization extent according to previous study. ${ }^{25}$ The lignin samples were labeled as $w 1$-EL, $w 2$-EL, $a 1$-EL and $a 2$-EL respectively to previous SE treatments. After lignin extraction, the solid and liquid phase were separated and filtrated. The solid residual was washed by a mixture of ethanol/water $(8 / 2$, by vol., $3 \times 50 \mathrm{~mL})$ at $60^{\circ} \mathrm{C}$ and then dried for $24 \mathrm{~h}$ at $40^{\circ} \mathrm{C}$. Three volumes of distilled water were added to the liquid phase, combined by the above washes to precipitate lignin fraction by centrifugation. Then, the extracted lignin was washed with distilled water and then dried for $48 \mathrm{~h}$ at $40^{\circ} \mathrm{C}$. Before the measurements, the 
lignin was purified by n-hexane (Soxhlet extraction) for six hours and then oven-dried at $40^{\circ} \mathrm{C}$ for $24 \mathrm{~h}$.

\section{Alkaline lignin (AL) isolation}

$25 \mathrm{~g}$ of oven-dried SE treated biomass were treated with a solution of $\mathrm{NaOH}$ (1\% by w.) for $2 \mathrm{~h}$ at $80^{\circ} \mathrm{C}$ with the liquid/solid ratio of $10 / 1$ (by vol.) to obtain $\mathrm{AL}$ fractions without any dramatic chemical modification on their structures under mild condition. $^{26,27}$ The lignin samples were labeled as $w 1-\mathrm{AL}, w 2-\mathrm{AL}, a 1-\mathrm{AL}$ and $a 2-\mathrm{AL}$ respectively to previous SE treatments. After alkaline pulping treatment, the pulp was separated by filtration. The residual was washed with distilled water to neutral phase and dried for $24 \mathrm{~h}$ at $40^{\circ} \mathrm{C}$. The black liquid was adjusted to $\mathrm{pH} 5.0-5.5$ with $6.0 \mathrm{M}$ hydrochloric acid and then centrifuged (4000g, $30 \mathrm{~min}$ ), washed with distilled water and dried for $48 \mathrm{~h}$ at $40^{\circ} \mathrm{C}$. Before the measurements, the lignin was purified by n-hexane (Soxhlet extraction) for six hours and then oven-dried at $40^{\circ} \mathrm{C}$ for $24 \mathrm{~h}$.

\section{Biomass composition contents}

$2 \mathrm{~g}$ milled wood powder (40 mesh) were extracted by toluene/ethanol (2/1 by vol.) with a Soxhlet extraction apparatus for six hours. The free extractive wood powders were used to measure the acid insoluble lignin and monomeric sugars content according to the standard TAPPI method T222 om-02 and NREL/TP-510-42618 c42622. The monomeric sugars in liquid fractions obtained from lignin hydrolysis were analyzed by using high-performance anion exchange chromatography coupled with pulsed amperometric detection (HPAE-PAD, ICS-3000 Dionex) with an analytical column Dionex CarboPac $^{\mathrm{TM}}$ PA-20 $(3 \times 150 \mathrm{~mm})$. 
Monosaccharides were eluted at $35^{\circ} \mathrm{C}$ and with a flowrate of $0.4 \mathrm{~mL} / \mathrm{min}$ with the following composition: pure water 99,2\%/250 mM NaOH 0,8\%: 0 20 min ; pure water $75 \% / 250 \mathrm{mM} \mathrm{NaOH} 20 \% / \mathrm{NaOAc}(1 \mathrm{M})-\mathrm{NaOH}(20 \mathrm{mM}) 5 \%$ 20 37 min ; pure water $40 \% / 250 \mathrm{mM} \mathrm{NaOH} 20 \% / \mathrm{NaOAc}(1 \mathrm{M})-\mathrm{NaOH}(20 \mathrm{mM}) 40 \% 37 \sim 41$ min. Each elution was followed by a wash and subsequent equilibration time. The standards for external sugars and uronic acids were utilized for analysis: fucose, glucose, xylose, galactose, mannose, rhamnose, arabinose and acid galacturonic .

\section{Lignin composition}

$5 \mathrm{mg}$ of purified (n-hexane) lignin were mixed with $0.125 \mathrm{~mL} \mathrm{H}_{2} \mathrm{SO}_{4}(72 \%)$ for $1 \mathrm{~h}$ at $30^{\circ} \mathrm{C}$. Then, $1.35 \mathrm{~mL}$ of distilled water was added the hydrolysis process was continued for $2.5 \mathrm{~h}$ by autoclaving at $105^{\circ} \mathrm{C}$. The residual solid was separated by filtration and dried for $24 \mathrm{~h}$ at $105^{\circ} \mathrm{C}$ before being weighed to determine the acid insoluble lignin (AIL) content. The liquid phase containing the monomeric sugars was analyzed by HPAE-PAD.

\section{HSQC NMR}

$200 \mathrm{mg}$ of lignin samples were dissolved in $0.4 \mathrm{~mL}$ of dimethylsulfoxide- $\mathrm{d}_{6}(99.8 \%)$

for the analysis of ${ }^{13} \mathrm{C}-{ }^{1} \mathrm{H}$ Heteronuclear Single Quantum Coherence (HSQC) NMR. The mixture was dispersed by ultrasound for $1 \mathrm{~h}$. The spectra were obtained by Bruker Avance III $400 \mathrm{MHz}$ at ambient temperature and the relaxation delay was 25 sec.

\section{${ }^{31}$ P NMR}

$25 \mathrm{mg}$ of dried and purified lignin samples were dissolved in $0.5 \mathrm{~mL}$ of a mixed 
solution of pyridine/deuterated chloroform (1.6/1.0, by vol.) in a $2 \mathrm{~mL}$ vial. $0.1 \mathrm{~mL}$ of chromium (III) acetylacetonate $(5.0 \mathrm{mg} / \mathrm{mL})$ and $0.1 \mathrm{~mL}$ of cyclohexanol $(10.85$ $\mathrm{mg} / \mathrm{mL}$ ) respectively as relaxation reagent and internal standard were added, followed by $0.1 \mathrm{~mL}$ of 2-chloro-4,4,5,5-tetramethyl-1,2,3-dioxaphospholane to obtain phosphitylated lignin according to previous reference. ${ }^{28}$ The spectra were obtained by Bruker Avance III HD $300 \mathrm{MHz}$ at ambient temperature and the relaxation delay was $2 \mathrm{~s}$.

\section{ATR-FTIR}

$20 \mathrm{mg}$ of dried lignin was analyzed by a Fourier transform infrared (ATR-FTIR) device with a total reflection mode (NICOLET 6700). The scanning range was $400 \sim 4000 \mathrm{~cm}^{-1}$ with a resolution of $4 \mathrm{~cm}^{-1}$.

\section{Size exclusion chromatography (SEC)}

The weight-average molecular weight $\left(\mathrm{M}_{\mathrm{w}}\right)$, number-average molecular weight $\left(\mathrm{W}_{\mathrm{n}}\right)$ and $\mathrm{M}_{\mathrm{w}} / \mathrm{W}_{\mathrm{n}}$ of lignin were measured by SEC. Analyses were performed using a Shimadzu Prominance system equipped with a UV detector at $280 \mathrm{~nm}$ and $254 \mathrm{~nm}$ on a column sequence consisting of a Shodex GPC KF-806L column followed by a phenogel $00 \mathrm{H}-0442-\mathrm{K} 0$ column. The separation was operated at $30^{\circ} \mathrm{C}$ and eluted with tetrahydrofuran (THF) at a flow rate of $0.7 \mathrm{~mL} / \mathrm{min}$. The derivatized lignin was dissolved in unstabilized THF $(1 \mathrm{mg} / \mathrm{mL})$, filtered through a $0.45 \mu \mathrm{m}$ filter and $20 \mu \mathrm{L}$ of the solution was then injected. Standard polystyrene samples were used to construct a calibration curve.

\section{Glyoxalated lignin/tannin resin}


The glyoxalated lignin was prepared following a previously described study. ${ }^{5} 1.00 \mathrm{~g}$ of SE lignin was slowly added to $1.30 \mathrm{~g}$ of distilled water in $6 \mathrm{ml}$ vial. Then, $1.14 \mathrm{~g}$ of sodium hydroxide solution (30\%, w/w) was added gradually to obtain a $\mathrm{pH}$ between 12 and 12.5 for better dissolving lignin powder. The mixture was then heated to $65^{\circ} \mathrm{C}$ and stirred with magnet for $30 \mathrm{~min}$ at this temperature on a hot plate. $0.60 \mathrm{~g}$ of $40 \%$ glyoxal/water solution was added in the mixture and then stirred continuously for $8 \mathrm{~h}$ at $65^{\circ} \mathrm{C}$. A $45 \%(\mathrm{w} / \mathrm{w})$ Mimosa tannin/water solution was prepared and its $\mathrm{pH}$ was adjusted to 10 with $33 \%$ (w/w) $\mathrm{NaOH} /$ water solution. Then, $30 \%$ (w/w) hexamine/water solution was added as a hardener $(6 \%(\mathrm{w} / \mathrm{w})$ of hexamine based on tannin). Then, the glyoxalated lignin was mixed with tannin solution (glyoxalated lignin $/$ tannin $=50 / 50 \mathrm{w} / \mathrm{w})$.

\section{Thermomechanical analysis (TMA)}

2-ply composites comprised by beech layers with the dimension of $22.15 \mathrm{~mm} \times 6.10$ $\mathrm{mm} \times 0.35 \mathrm{~mm}($ length $\times$ width $\times$ height $)$ and $22 \mathrm{mg}$ of glyoxalated lignin/tannin resin were prepared in order to evaluate the reaction of lignin with polymers and the property of wood-resin joint. The three-points bending mechanical properties of 2-ply composites were measured with the relationship of temperature by the device of TMA (TMA40, Mettler Toledo, Columbus, USA). The rate of heating was $10^{\circ} \mathrm{C} / \mathrm{min}$ and the modulus of elasticity (MOE) was recorded for wood-resin joint.

\section{Results and discussions}

\section{SE treated biomass, residual and lignin compositions and yield}


Different pre-impregnation methods ( $w$ and $a$ ) and two SFs (SF1: 3.05 and SF2: 3.64) were selected for preparing SE treated biomass in this study. The chemical compositions for SE-treated biomass are given in Table 1. After SE treatment, an increase in lignin and cellulose content and a decrease in hemicellulose content were obtained compared to the untreated beech sawdust components. As expected, a decrease in hemicellulose for the highest SF was observed, especially after $a$-SE treatment. This result confirms that the hydrolysis of hemicellulosic sugars is favored in acidic conditions and at higher severity. Similar results were observed in the previous investigations. ${ }^{29,30}$ Alkaline and ethanol delignification processes were performed for SE treated biomass and the composition of the delignified pulp are given in Table 1. As expected, a significant decrease in the lignin and hemicellulose and an increase in the cellulose contents were observed after extraction using both isolation methods; higher decrements were observed for the SE pulps isolated after $a$-SE treatment especially with higher SF (a2-AL and $a 2-\mathrm{EL})$. Lower lignin and hemicellulose contents in the solid residues were observed with ethanol delignification process compared to alkaline process and the difference of these contents between both processes decreased for $a$-SE treatment, especially for higher SF. These observations can be explained by a more important deconstruction of the lignocellulosic complex after $a$-SE. A higher extractability of non-cellulosic materials was observed under ethanol-organosolv conditions while higher degradation of cellulosic materials occurred for alkaline delignification process. A comparable observation was made in a previous investigation and this would play a significant 
role on the compositions of solid residues and lignins. ${ }^{31}$ As a result, washed pulps with a higher cellulose content were produced using the ethanol process compared to the alkaline procedure.

The lignin yields isolated after delignification of SE-treated solid residues are given in Table 2. For all the pulps, the alkali delignification led to higher lignin yields than ethanol-organosolv delignification and an increased difference was observed for $a$-SE treatment especially for the highest SF because of the high destruction in these latter conditions. $^{15}$ The lignin compositions were investigated (after acid hydrolysis) in terms of acid-insoluble lignin (AIL) and monomeric sugars and the results are shown in Table 2. We can notice that all the recovered fractions have very high AIL contents (>95\%), attesting to the purity of the isolated SE lignins. Besides, in accordance with previous study, some residual carbohydrates probably originating from lignin-carbohydrate complex (LCC) have been detected. ${ }^{32}$ In accordance with previous works, higher carbohydrate contents were obtained from alkali delignification. $^{21,33}$ The highest sugars contaminations were observed for $w$-SE treated biomass after alkali delignification (w1-AL 2.28\% and $w 2$-AL 2.08\%) and the lowest for ethanol-organosolv delignification (a1-EL 0.77\%, w2-EL 0.84\%, a2-EL $0.92 \%)$. The main detected sugars are xylose and glucose. Interestingly, an increased glucose content was observed for $a$-SE treatment and alkali delignification ( $a 1$-AL and $a 2-\mathrm{AL}$ ) suggesting a partial degradation of cellulose polymer in these conditions. For MWL, small quantities of carbohydrate contents were detected in the HSQC NMR spectrum shown in the supplementary material (Figure S1). The presence of 
residual carbohydrates $(<5 \%, \mathrm{w} / \mathrm{w})$ in MWLs was observed in previous investigations.$^{34,35}$

\section{Chemical structures for lignins}

In order to further investigate the chemical structures of the different lignin fractions recovered, two-dimensional heteronuclear single-Quantum correlation NMR (HSQC) measurement was utilized in this study. The HSQC NMR spectra of ethanol-organosolv and alkaline lignin (ELs and ALs) were shown in Figure 2 and Figure 3. The main assignments for ${ }^{13} \mathrm{C} /{ }^{1} \mathrm{H}$ cross-signals based on previous literature were listed in Table 3 and the chemical structure for these unites were presented in Table 4. Three important regions were considered in this study including (I) the region of aliphatic side chains $(\delta \mathrm{C} / \delta \mathrm{H} 5-38 / 0.5-2.5)$, (II) the region of aliphatic oxygenated side chains $(\delta \mathrm{C} / \delta \mathrm{H} 45-105 / 2.5-5.8)$ and (III) the aromatic region $(\delta \mathrm{C} / \delta \mathrm{H}$ $95-135 / 5.8-8.0)$.

The amounts of $\beta-\operatorname{aryl}-$ ether $(\mathrm{A}: \beta-\mathrm{O}-4)$, phenylcoumaran $(\mathrm{B}: \beta-5)$ and resinol $(\mathrm{C}$ : $\beta-\beta)$ linkages were of great significance to determine the depolymerization extent for lignin structure. Based on literature data, a semi-quantative HSQC analysis was performed in order to quantify the effect of the whole process on the lignins structure. ${ }^{36}$ The cross signals of $\delta \mathrm{C} / \delta \mathrm{H} 72.10 / 4.78, \delta \mathrm{C} / \delta \mathrm{H} 87.59 / 5.53$ and $\delta \mathrm{C} / \delta \mathrm{H}$ 85.33/4.67 ascribed to $\mathrm{A}_{\alpha}, \mathrm{B}_{\alpha}, \mathrm{C}_{\alpha}$ were used to calculate the abundance of main linkages with the aromatic units of $\delta \mathrm{C} / \delta \mathrm{H} 104.85 / 6.65\left(\mathrm{~S}_{2,6}\right)$ and $\delta \mathrm{C} / \delta \mathrm{H} 111.46 / 7.02$ $\left(\mathrm{G}_{2}\right)$ expressed as internal standard. Other related regions were also calculated using the cross signals of $\delta \mathrm{C} / \delta \mathrm{H} \quad 53.70 / 3.53 \quad\left(\mathrm{~B}_{\beta}\right), \quad \delta \mathrm{C} / \delta \mathrm{H} \quad 54.35 / 3.04 \quad\left(\mathrm{C}_{\beta}\right), \quad \delta \mathrm{C} / \delta \mathrm{H}$ 
71.13-71.77/3.91-4.22 $\left(\mathrm{C}_{\gamma}\right), \delta \mathrm{C} / \delta \mathrm{H} 81.13 / 4.59\left(\mathrm{~A}_{\beta} \mathrm{G}\right), \delta \mathrm{C} / \delta \mathrm{H}$ 84.36-86.29/4.14-4.34 $\left(\mathrm{A}_{\beta} \mathrm{S}\right)$ and $\delta \mathrm{C} / \delta \mathrm{H} 87.59 / 5.53\left(\mathrm{~B}_{\alpha}\right)$. Qualification analysis was conducted for these main linkages and aromatic regions as displayed in Table 4. The data corresponding to MWL which can be considered as representative of native lignin.

A significant decrease of $\beta-\mathrm{O}-4$ linkages was observed for SE lignins compared to MWL. As expected, the lowest $\beta-\mathrm{O}-4$ contents were obtained for $a 2-\mathrm{EL}$ and $a 2-\mathrm{AL}$ (16.83\% and $17.96 \%$ respectively) extracted from acid-impregnated wood using the higher SF for SE treatment. This result is explained by the well-known acidolytic $\beta-\mathrm{O}-4$ lignin breakdown. Similar results were also obtained for $\beta-5$ and $\beta-\beta$ linkages. 18,12

It clearly appears from Table $\mathbf{4}$ that the delignification process (ethanol-organosolv or alkaline) also significantly impacted the lignin structure especially at low SE severity. The lignin recovered by ethanol-organosolv extraction retained less $\beta$-aryl-ether units $\left(\mathrm{A}_{\alpha} \approx 38 \%\right.$ and $69 \%$ for $w 1$-EL and $w 1$-AL respectively) probably because of the higher temperature involved for the ethanol-organosolv delignification promoting the $\beta-\mathrm{O}-4$ deconstruction.

In order to investigate the reduction level for $\beta-\mathrm{O}-4, \beta-5$ and $\beta-\beta$ linkages inELs and ALs, change ratios for these linkages were calculated based on MWL values and reported in Figure 5. As expected, a higher reduction levels were obtained using the harshest SE conditions (a2-lignins) (change ratios > 79\%). Besides, under the same SE condition, it appears from Fig. 5 that the lignin recovery processes affected the inter-unit linkages in a different way. Based on previous papers, these results can be 
attributed to the fact that alkaline extraction has more significant degrading effect on lignin substructures especially phenylcoumaran moiety than ethanol extraction. ${ }^{7,21}$

In contrast, the organosolv delignification has led to a greater degradation of $\beta-\mathrm{O}-4$ and $\beta-\beta$ linkages especially after water impregnation. Thus, for $\beta-\mathrm{O}-4$ units change ratios of $\approx 20 \%$ and $\approx 60 \%$ has been observed for $w 1$-AL and $w 1$-EL respectively.

In the aliphatic oxygenated side chains region, two additional signals were found in ethanol-organosolv lignins spectra ( $w$-ELs and $a$-ELs) at $\delta \mathrm{C} / \delta \mathrm{H} 64.67 / 3.36\left(\mathrm{~A}_{\alpha}{ }_{\alpha}\right)$ and 81.13/4.59 $\left(\mathrm{A}_{\beta} \mathrm{G}\right)$. Based on previous papers, these signals correspond respectively to

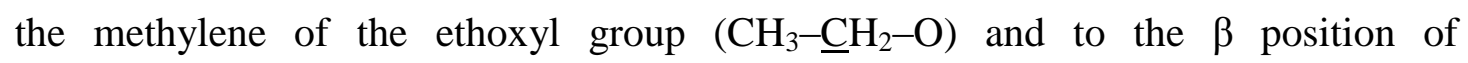
$\alpha-$ ethoxylated $\left(\mathrm{A}_{\alpha}-O E t\right)$. The presence of the $O E t$ group in the lignin structure is also confirmed by an additional cross signal in the aliphatic region (I) at $\delta \mathrm{C} / \delta \mathrm{H} 15.56 / 1.14$ assigned to $\mathrm{CH}_{3}-\mathrm{CH}_{2}-\mathrm{O} .{ }^{37,}{ }^{38}$ Cross-signals assigned to carbohydrates were also detected in this region and have been assigned based on previous literatures. ${ }^{39,40}$ D-xylose and D-Glucose units were labeled as X, Glu in the spectra. In accordance with the chromatographic results previous discussed (Table 2), higher carbohydrates contents were detected in alkaline lignins ( $w$-ALs and $a$-ALs) than in ethanol-organosolv lignins ( $w$-ELs and $a$-ELs) especially for the lowest severity ( $w 1$ and $a 1$ ).

In the aromatic region, more condensed structures for $\mathrm{S}$ and $\mathrm{G}$ units were observed for ethanol-organosolv lignins as displayed in the cross signals of $\delta \mathrm{C} / \delta \mathrm{H} 107.46 / 6.43$ $\left(\mathrm{S}_{2,6} \mathrm{Con}.\right)$ and $\delta \mathrm{C} / \delta \mathrm{H} 112.48 / 6.78\left(\mathrm{G}_{2} \mathrm{Con}.\right)$, the high temperature involved in delignification process promoting recondensation reactions. In addition, higher S/G 
ratios were obtained for all lignins after SE treatment, ALs displaying higher S/G ratios than ELs, especially for $a$-SE and higher SF treatment. These results indicated that increased depolymerization extent was obtained for both lignins extracted from SE treated biomass. $a$-SE treatment has a positive effect on the depolymerization and condensation for lignin structure especially for higher SF treatment as stated similarly in previous study. ${ }^{14,41}$

The ${ }^{31} \mathrm{P}$ NMR spectra of the phosphitylated lignins are given in Figure $\mathbf{6}$ and $\mathbf{7}$ in order to further investigate their structure. The NMR experiments were carried out according to a previously described method in presence of cyclohexanol as an internal standard and analyzed with quantitative ${ }^{31} \mathrm{P}$ NMR with the range from $130-148 \mathrm{ppm} .{ }^{42}$ The abundance of aliphatic $-\mathrm{OH}(\mathrm{ROH})$, condensed phenolic $-\mathrm{OH}(\mathrm{PhOH})$, syringyl $-\mathrm{OH}$, guiacyl $-\mathrm{OH}, \mathrm{p}$-hydroxy $-\mathrm{OH}$ and $-\mathrm{COOH}$ were measured and are listed in Table 5. As expected, a significant increase in phenolic - $\mathrm{OH}$ groups were observed after SE confirming the $\beta-\mathrm{O}-4$ acidolytic breakdown. It is noteworthy to note that for ethanol-organosolv lignin ( $w 1$-EL, w2-EL and $a 1$-EL), higher $\mathrm{PhOH} / \mathrm{ROH}$ ratios and condensed phenolic $-\mathrm{OH}$ were observed compared to ALs. Based on previous results, ${ }^{43}$ these observations are in accordance with (1) the extensive lignin breakdown using EL delignification conditions accompanied with recondensation reactions previously observed par HSQC NMR, (2) dehydration reactions of aliphatic OH of the lateral chain involved in organosolv delignification performed at high temperature. The higher $-\mathrm{COOH}$ content in ALs can be explained by saponification reactions of esters groups in lignin. 
FTIR spectra for ELs and ALs were shown in Figure $\mathbf{8}$ and the bands assignments were listed in Table 6 according to a previous study. ${ }^{7}$ The vibrations for aromatic ring attributed to phenylpropane skeleton were at 1594,1506 and $1422 \mathrm{~cm}^{-1}$. The wide band at $3440 \mathrm{~cm}^{-1}$ was assigned to $-\mathrm{OH}$ stretching vibration and the bands at 2942 , 2882, 2840 and $1457 \mathrm{~cm}^{-1}$ to $\mathrm{C}-\mathrm{H}\left(\mathrm{CH}_{3}\right.$ and $\left.\mathrm{CH}_{2}\right)$. It was confirmed that no dramatic changes were found for lignin aromatic structure during the SE treatment and the delignification process as compared to MWL. As expected and in accordance with ${ }^{31} \mathrm{P}$ NMR results, a decrease of $\mathrm{OH}$ and $\mathrm{C}-\mathrm{O}$ bands (at $3440 \mathrm{~cm}^{-1}$ and $1026 \mathrm{~cm}^{-1}$ respectively) was observed in SE lignins with a higher decrease for ALs. The increase of the band at $1370 \mathrm{~cm}^{-1}(\mathrm{PhO}-\mathrm{H})$ for ELs (especially for a2-lignins) can be explained by the acid-calalyzed cleavage of $\beta-\mathrm{O}-4$ linkages previously observed in these conditions.

\section{Molecular mass distribution}

The weight-average molecular weight $\left(M_{w}\right)$, number-average molecular number $\left(M_{n}\right)$ and polydispersities are given in Table 7. From all the data, a clear trend can be observed regarding the effect of the delignification method on the molecular mass distributions. As shown in molecular distribution chromatograms and compared with MWL, SE lignin spectra moved to lower molecular weight region (Figure 9). This result was due to the lignin breakdown previously described. Whatever the SE 
conditions, the lignin recovered by ethanol-organosolv process displayed higher molecular mass and higher polydispersity than ALs. This observation is in accordance with the NMR results and with previously described papers, the high temperature involved for the ethanol-organosolv delignification promoting recondensation reaction.

\section{Thermal property}

Thermomechanical Analysis (TMA) is an effective technology for evaluating the chemical reactivity of polymers to cross-linking reactions and their hardening properties. $^{44,45}$ Adhesive formaldehyde-free formulations composed of a mixture glyoxalated SE lignin/tannin 50/50 have been prepared and tested according to a technique already described. ${ }^{5}$ The Figure $\mathbf{1 0}$ gives the curves of the modulus of elasticity (MOE) of a wood bonded joint as a function of the temperature for all the SE lignin fractions of this study. The curve corresponding to pure tannin was also given.

Interestingly, the parameters of the SE treatment (SF 1,2, impregnation $a, w$ ) have a huge influence on the hardening properties. Based on the results presented above, we can observe that the SE conditions favoring the lignin deconstruction and the $\beta-\mathrm{O}-4$ linkages cleavage (acid catalyst, high temperature) produce lignin fractions with higher hardening reactivity. ${ }^{47,5}$ Moreover, it also appears from Figure 10 that the delignification process clearly affected the cross-linking reactivity. For all the samples, the formulations including ALs exhibited higher performance than those with ELs. As a result, $a 2-\mathrm{AL}$ extracted after $a$-SE treatment at high SF with alkali delignification 
led to an adhesive formulation displaying a very good performance with $\mathrm{MOE}_{\max } \approx$ $6000 \mathrm{MPa}$. This value is even better than pure tannin and better than lignin-based adhesive formulations previously reported. In comparable conditions, a $\mathrm{MOE}_{\max } \approx$ $4500 \mathrm{MPa}$ was reported for organosolv lignin-based resins. ${ }^{5,45}$ Alkaline lignin was also experimented with synthetic phenol-formaldehyde resin and/or pMDI with $\mathrm{MOE}_{\max } \approx 2000 \sim 3000 \mathrm{MPa}^{6}$ A possible explanation could be the lower molecular mass of the ALs (Table 7) and its lower recondensation degree.

\section{Conclusion}

In this study it was demonstrated that the delignification (ethanol-organosolv or alkali) of exploded beech wood greatly impacted the properties of the lignin recovered especially for SE performed at low severity. Using an alkali treatment, higher yields were obtained and the lignin retained more aryl-ether units and residual sugars, displayed lower molecular mass and polydispersity, is less recondensed and exhibited higher cross-linking reactivity in green adhesive formulations. We can conclude that, in a biomass-to-biofuel process, an alkali solid-liquid extraction performed after the SE in an aqueous medium at moderate temperature could allow the recovery of high quality SE lignin for green adhesive applications. We hope that this study will contribute to propose an economically valuable utilization of SE lignin which is currently largely underexploited.

\section{Acknowledgements}


The authors are appreciated for the funding from the National Key R\&D Program of China [grant numbers: 2017YFC0703501]. The study was supported by the Doctorate Fellowship Foundation of Nanjing Forestry University, the Postgraduate Research \&Practice Innovation Program of Jiangsu Province [grant numbers: KYCX18_0962], the project funded by the National First-class Disciplines and the Priority Academic Program Development of Jiangsu Higher Education Institutions (PAPD). LERMAB is supported by the French National Research Agency through the Laboratory of Excellence ARBRE (ANR-12-LABXARBRE-01) as well. The first author also appreciated for the grand from the China Scholarship Council (CSC). The authors greatly acknowledge the Plateforme de RMN de l'Institut Jean Barriol, Université de Lorraine.

\section{References}

1. Zhao, S.; Abu-Omar, M. M., Synthesis of Renewable Thermoset Polymers through Successive Lignin Modification Using Lignin-Derived Phenols. Acs Sustainable Chemistry \& Engineering, acssuschemeng.7b00440.

2. Rodrigues, A. E.; Pinto, P. C. d. O. R.; Barreiro, M. F.; Esteves da Costa, C. A.; Ferreira da Mota, M. I.; Fernandes, I., An Integrated Approach for Added-Value Products from Lignocellulosic Biorefineries (Vanillin, Syringaldehyde, Polyphenols and Polyurethane) || Polyurethanes from Recovered and Depolymerized Lignins. 10.1007/978-3-319-99313-3 (Chapter 3), 85-117.

3. Nicastro, K. H.; Kloxin, C. J.; Epps, T. H., Potential Lignin-Derived Alternatives to Bisphenol A in Diamine-Hardened Epoxy Resins. ACS Sustainable Chemistry \& Engineering 2018.

4. Zhang, Y.; Wu, J.-Q.; Li, H.; Yuan, T.-Q.; Wang, Y.-Y.; Sun, R.-C., Heat Treatment of Industrial Alkaline Lignin and its Potential Application as an Adhesive for Green Wood-Lignin Composites. ACS Sustainable Chemistry \& Engineering 2017, 5 (8), 7269-7277.

5. Dabbabi, I.; Gimello, O.; Elaloui, E.; Quignard, F.; Brosse, N., Organosolv Lignin-Based Wood Adhesive. Influence of the Lignin Extraction Conditions on the Adhesive Performance. Polymers 2016, 8,340 .

6. Mansouri, N. E. E.; Pizzi, A.; Salvadó, J., Lignin-based wood panel adhesives without formaldehyde. 65 (1), 65-70.

7. Tejado, A.; Peña, C.; Labidi, J.; Echeverria, J. M.; Mondragon, I., Physico-chemical characterization of lignins from different sources for use in phenol-formaldehyde resin synthesis. Bioresource Technol 2007, 98 (8), 1655-1663.

8. Ono, H. K.; Sudo, K. In Wood Adhesives from Phenolysis Lignin, 1989.

9. Costa, C. A. E.; Pinto, P. C. R.; Rodrigues, A. E., Radar Tool for Lignin Classification on the Perspective of Its Valorization. Ind Eng Chem Res, 150731152018008.

10. Alvira, P.; Tomas-Pejo, E.; Ballesteros, M.; Negro, M., Pretreatment technologies for an efficient bioethanol production process based on enzymatic hydrolysis: A review. Bioresource Technol 2010, $101,4851-61$.

11. Hendriks, A. T. W. M.; Zeeman, G., Pretreatments to enhance the digestibility of lignocellulosic biomass. Bioresource Technol 2009, 100 (1), 10-18. 
12. Sharma, S.; Kumar, R.; Gaur, R.; Agrawal, R.; Gupta, R. P.; Tuli, D. K.; Das, B., Pilot scale study on steam explosion and mass balance for higher sugar recovery from rice straw. Bioresource Technol 2015, 175, 350-357.

13. Li, J.; Gellerstedt, G. r.; Toven, K., Steam explosion lignins; their extraction, structure and potential as feedstock for biodiesel and chemicals. 100 (9), 2556-2561.

14. Obame, S. N.; Ziegler-Devin, I.; Safou-Tchima, R.; Brosse, N., Homolytic and Heterolytic Cleavage of $\beta$-Ether Linkages in Hardwood Lignin by Steam Explosion. J Agr Food Chem 2019, 67 (21), 5989-5996

15. Auxenfans, T.; Crônier, D.; Chabbert, B.; Paës, G., Understanding the structural and chemical changes of plant biomass following steam explosion pretreatment. Biotechnology for Biofuels 2017, 10. 16. Martín-Sampedro, R.; Capanema, E.; Hoeger, I.; Villar, J.; Rojas, O., Lignin Changes after Steam Explosion and Laccase-Mediator Treatment of Eucalyptus Wood Chips. J Agr Food Chem 2011, 59, 8761-9.

17. Donohoe, B. S.; Decker, S. R.; Tucker, M. P.; Himmel, M. E.; Vinzant, T. B., Visualizing lignin coalescence and migration through maize cell walls following thermochemical pretreatment. Biotechnology \& Bioengineering 101 (5), 913-925.

18. Donaldson, L. A.; Kky, W.; Mackie, K. L., Ultrastructure of steam-exploded wood. 1988, 22 (2), 103-114.

19. Li, J.; Henriksson, G.; Gellerstedt, G., Lignin depolymerization/repolymerization and its critical role for delignification of aspen wood by steam explosion. Bioresource Technol 2007, 98 (16), 3061-3068.

20. Košíková, B.; Mlynár, J.; Zákutná, L.; Joniak, D.; Micko, M., The Relationship between Ultrastructure and Lignin Extractability of Steamed Hardwoods. In Holzforschung - International Journal of the Biology, Chemistry, Physics and Technology of Wood, 1990; Vol. 44, p 249.

21. Sun, S.-N.; Cao, X.-F.; Xu, F.; Sun, R.-C.; Jones, G. L., Structural Features and Antioxidant Activities of Lignins from Steam-Exploded Bamboo (Phyllostachys pubescens). J Agr Food Chem 2014, 62 (25), 5939-5947.

22. Matsakas, L.; Nitsos, C.; Raghavendran, V.; Yakimenko, O.; Persson, G.; Olsson, E.; Rova, U.; Olsson, L.; Christakopoulos, P., A novel hybrid organosolv: steam explosion method for the efficient fractionation and pretreatment of birch biomass. Biotechnology for Biofuels 2018, 11 (1), 160.

23. Hage, R. E.; Brosse, N.; Sannigrahi, P.; Ragauskas, A., Effects of process severity on the chemical structure of Miscanthus ethanol organosolv lignin. 95 (6), 997-1003.

24. Wang, G.; Chen, H., Enhanced lignin extraction process from steam exploded corn stalk. Separation \& Purification Technology 157, 93-101.

25. Issam, D.; Olinda, G.; Elimame, E.; Fran?oise, Q.; Nicolas, B., Organosolv Lignin-Based Wood Adhesive. Influence of the Lignin Extraction Conditions on the Adhesive Performance. Polymers 8 (9), 340-.

26. Nagieb, Z. A., Effect of temperature on the soda and kraft cooking of corn stalks. J Appl Polym Sci 1986, 31 (6), 1609-1617.

27. Li, H.-Y.; Sun, S.-N.; Wang, C.-Z.; Sun, R.-C., Structural and dynamic changes of lignin in Eucalyptus cell walls during successive alkaline ethanol treatments. Industrial Crops \& Products 74, 200-208. 
28. Granata, A.; Argyropoulos, D. S., 2-Chloro-4,4,5,5-tetramethyl-1,3,2-dioxaphospholane, a Reagent for the Accurate Determination of the Uncondensed and Condensed Phenolic Moieties in Lignins. J Agr Food Chem 1995, 43 (6), 1538-1544.

29. Kang, Y.; Bansal, P.; Realff, M.; Bommarius, A., SO2-catalyzed steam explosion: The effects of different severity on digestibility, accessibility, and crystallinity of lignocellulosic biomass. Biotechnol Progr 2013, 29.

30. Kumar, L.; Chandra, R.; Chung, P.; Saddler, J., Can the same steam pretreatment conditions be used for most softwoods to achieve good, enzymatic hydrolysis and sugar yields? Bioresource Technol 2010, 101, 7827-7833.

31. Dimos, K.; Paschos, T.; Louloudi, A.; Kalogiannis, K.; Lappas, A.; Papayannakos, N.; Kekos, D.; Mamma, D., Effect of Various Pretreatment Methods on Bioethanol Production from Cotton Stalks. Fermentation 2019, 5, 5.

32. Huijgen, W. J. J.; Telysheva, G.; Arshanitsa, A.; Gosselink, R. J. A.; de Wild, P. J., Characteristics of wheat straw lignins from ethanol-based organosolv treatment. Ind Crop Prod 2014, 59, 85-95.

33. Constant, S.; Wienk, H.; Frissen, A.; De Peinder, P.; Boelens, R.; Van Es, D.; Grisel, R.; Weckhuysen, B.; Huijgen, W.; Gosselink, R.; Bruijnincx, P., New insights into the structure and composition of technical lignins: A comparative characterisation study. Green Chem 2016, 18.

34. Fengel, D., Chemical Studies on the Wood of Quebracho colorado. (Schinopsis balansae Engl.). Part 2. Investigations of the Lignin. In Holzforschung - International Journal of the Biology, Chemistry, Physics and Technology of Wood, 1991; Vol. 45, p 395.

35. Huang, C.; He, J.; Du, L.; Min, D.; Yong, Q., Structural Characterization of the Lignins from the Green and Yellow Bamboo of Bamboo Culm (Phyllostachys pubescens). J Wood Chem Technol 2016, 36 (3), 157-172.

36. Haiwei, G.; Miles-Barrett, D. M.; Neal, A. R.; Zhang, T.; Li, C.; Westwood, N. J., Unravelling the Enigma of LigninOX: Can the Oxidation of Lignin be Controlled? Chemical Science, 10.1039.C7SC03520A.

37. Guo, Y.; Zhou, J.; Wen, J.; Sun, G.; Sun, Y., Structural transformations of triploid of Populus tomentosa Carr. lignin during auto-catalyzed ethanol organosolv pretreatment. Ind Crop Prod 2015, 76, $522-529$

38. Wang, X.; Guo, Y.; Zhou, J.; Sun, G., Structural changes of poplar wood lignin after supercritical pretreatment using carbon dioxide and ethanol-water as co-solvents. Rsc Advances 7 (14), 8314-8322.

39. Chadni, M.; Grimi, N.; Bals, O.; Ziegler-Devin, I.; Brosse, N., Steam explosion process for the selective extraction of hemicelluloses polymers from spruce sawdust. Ind Crop Prod 2019, 141, 111757.

40. Moine, C.; Krausz, P.; Chaleix, V.; Sainte-Catherine, O.; Gloaguen, V., Structural Characterization and Cytotoxic Properties of a 4- O -Methylglucuronoxylan from Castanea sativa. J Nat Prod 2007, 70 (1), 60-66.

41. Marques, A.; Rencoret, J.; Gutiérrez, A.; del Río, J.; Pereira, H., Ferulates and lignin structural composition in cork. Holzforschung 2015, 0 .

42. Wörmeyer, K.; Ingram, T.; Saake, B.; Brunner, G.; Smirnova, I., Comparison of different pretreatment methods for lignocellulosic materials. Part II: Influence of pretreatment on the properties of rye straw lignin. Bioresource Technol 2011, 102 (5), 4157-4164. 
43. El Hage, R.; Brosse, N.; Sannigrahi, P.; Ragauskas, A., Effect of the Severity of the Ethanol Organosolv Process on the Chemical Structure of Ethanol Organosolv Miscanthus Lignins. Polymer Degradation and Stability 2010, 95, 997-1003.

44. Hussin, M. H.; Rahim, A. A.; Mohamad Ibrahim, M. N.; Brosse, N., Physicochemical characterization of alkaline and ethanol organosolv lignins from oil palm (Elaeis guineensis) fronds as phenol substitutes for green material applications. Ind Crop Prod 2013, 49, 23-32.

45. Mansouri, H. R.; Navarrete, P.; Pizzi, A.; Tapin-Lingua, S.; Benjelloun-Mlayah, B.; Pasch, H.; Rigolet, S., Synthetic-resin-free wood panel adhesives from mixed low molecular mass lignin and tannin. European Journal of Wood and Wood Products 2011, 69 (2), 221-229.

46. Wang, G.; Chen, H., Phenolic foam prepared by lignin from a steam-explosion derived biorefinery of corn stalk. Chinese Journal of Biotechnology 2014, 30, 901-910. 


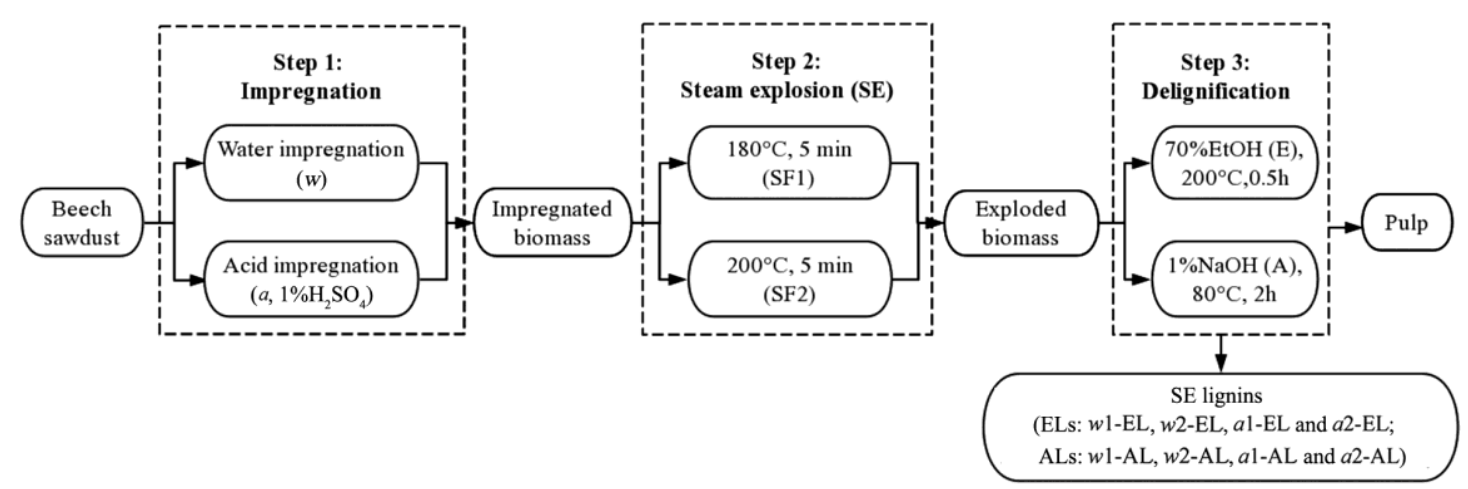

Figure 1. The diagram for preparing SE treated biomass and delignification process. 
aliphatic region (I) aliphatic oxygenated region(II) aromatic region (III)

(a) $w 1$-EL

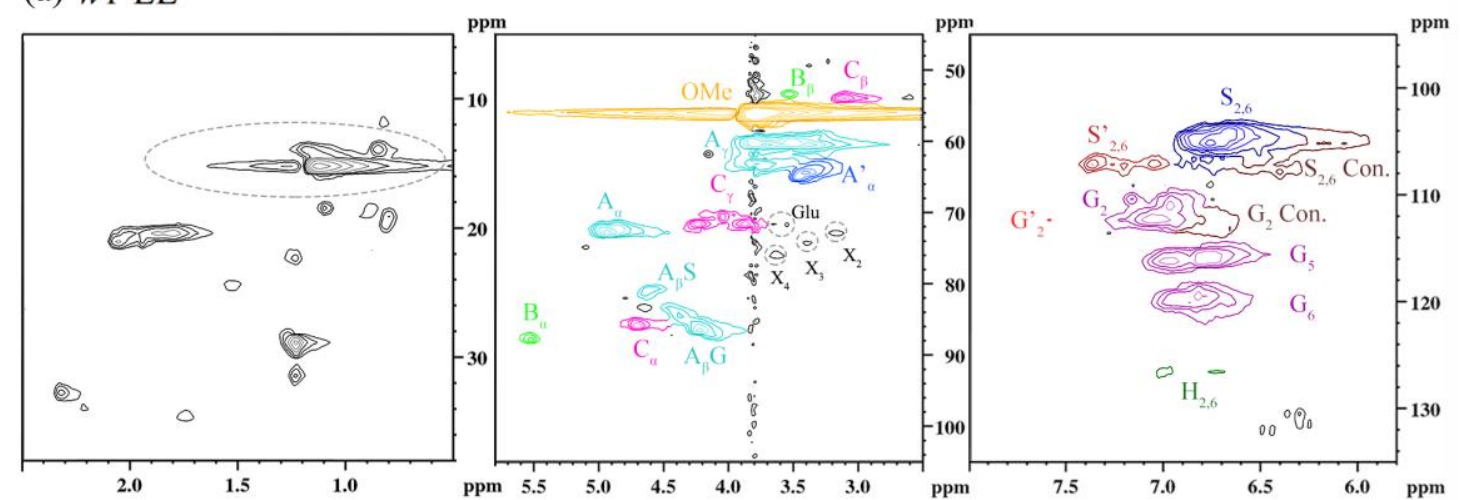

(b) $w 1-\mathrm{AL}$
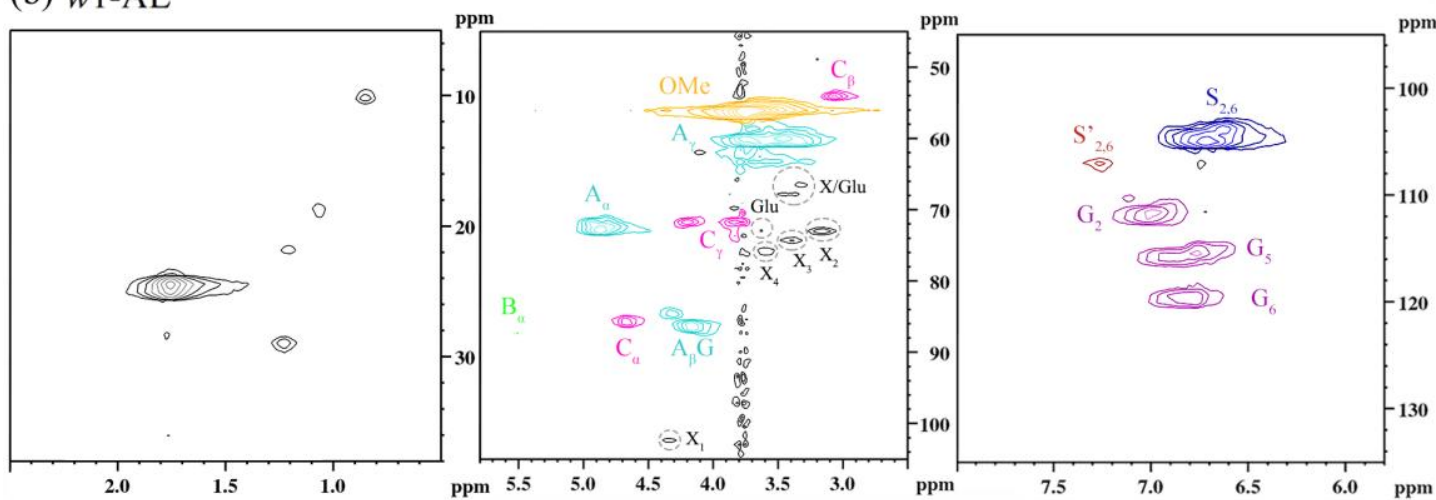

(c) $w 2$-EL
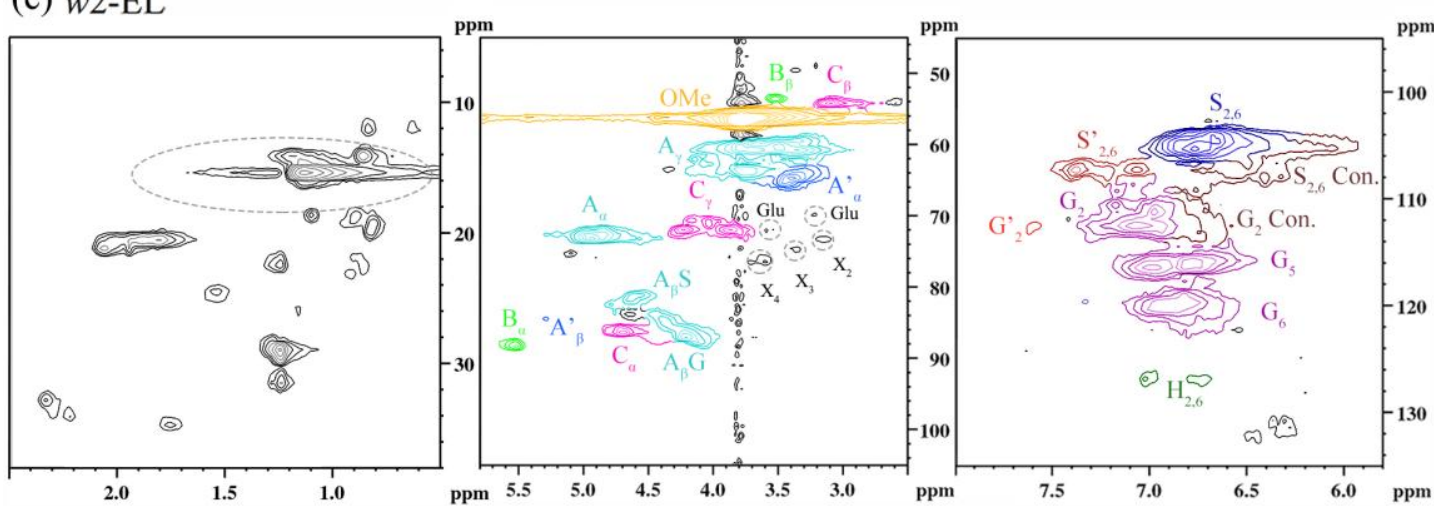

(d) $w 2-\mathrm{AL}$
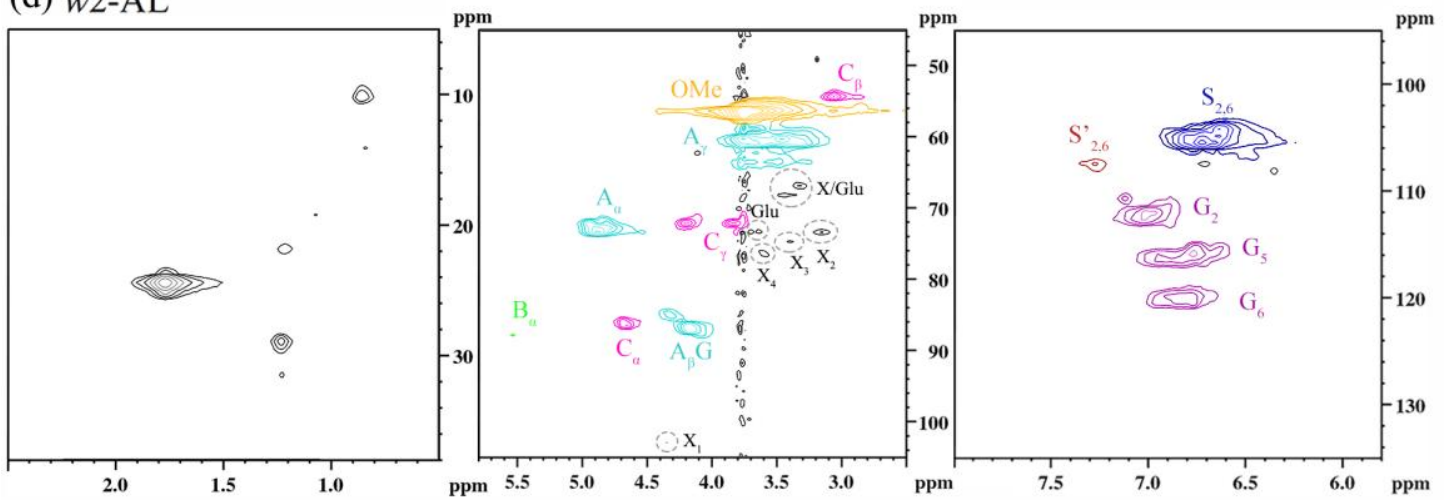

Figure 2. The HSQC NMR spectra for (a) $w 1$-EL, (b) $w 1$-AL, (c) $w 2-E L$ and (d)w2-AL and three main regions for each lignin. 
aliphatic region (I) aliphatic oxygenated region (II) aromatic region (III)

(a) a1-EL

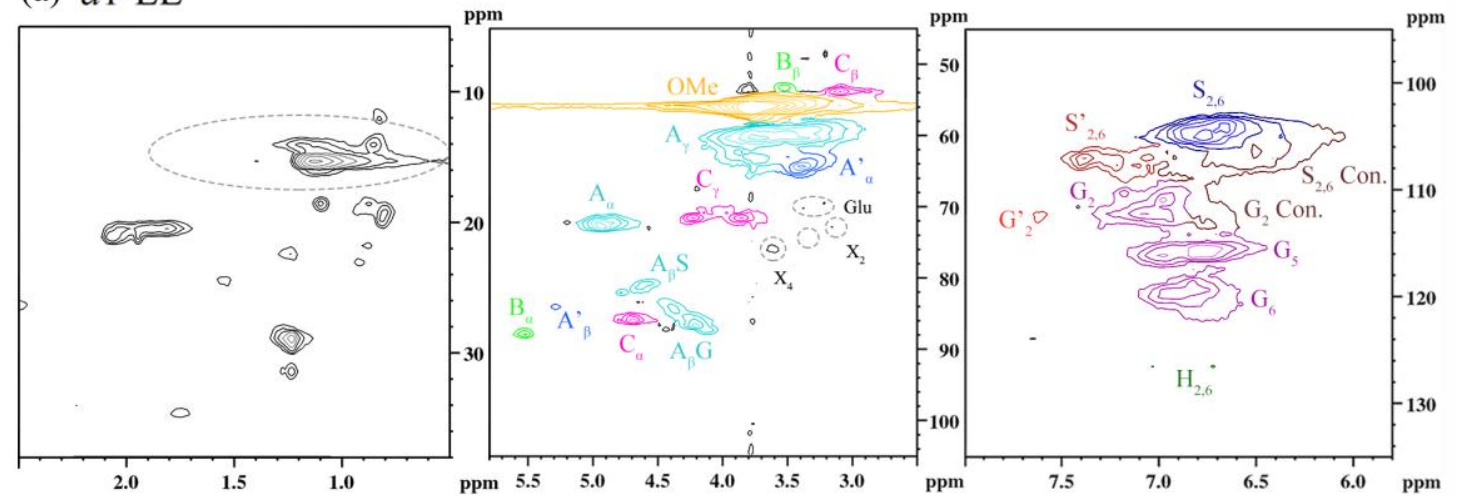

(b) $a 1-\mathrm{AL}$
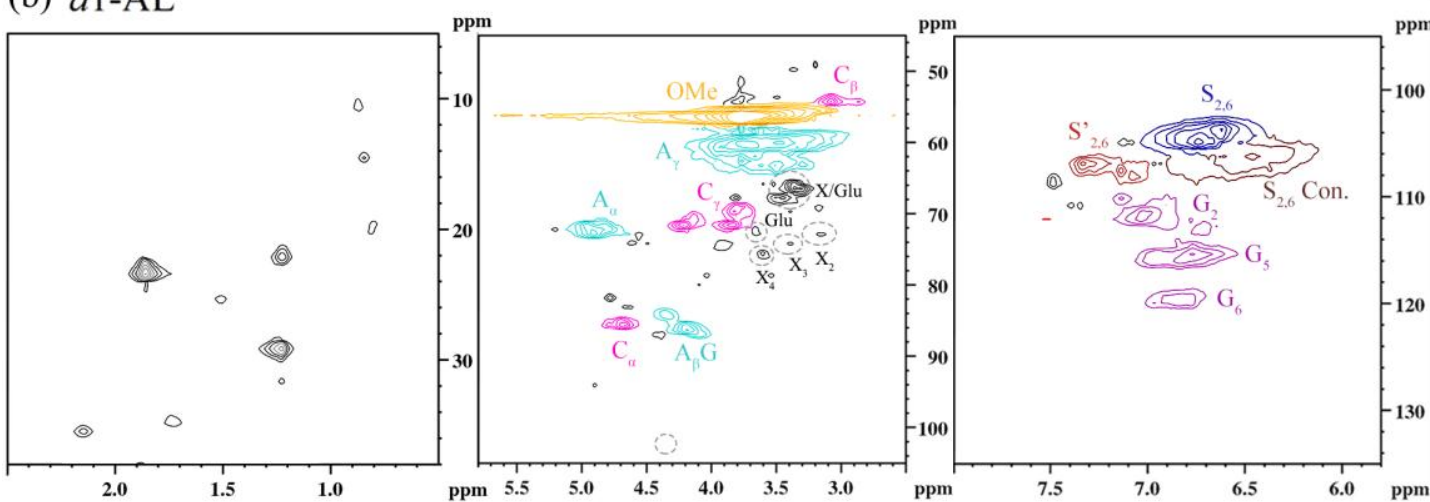

(c) $a 2$-EL
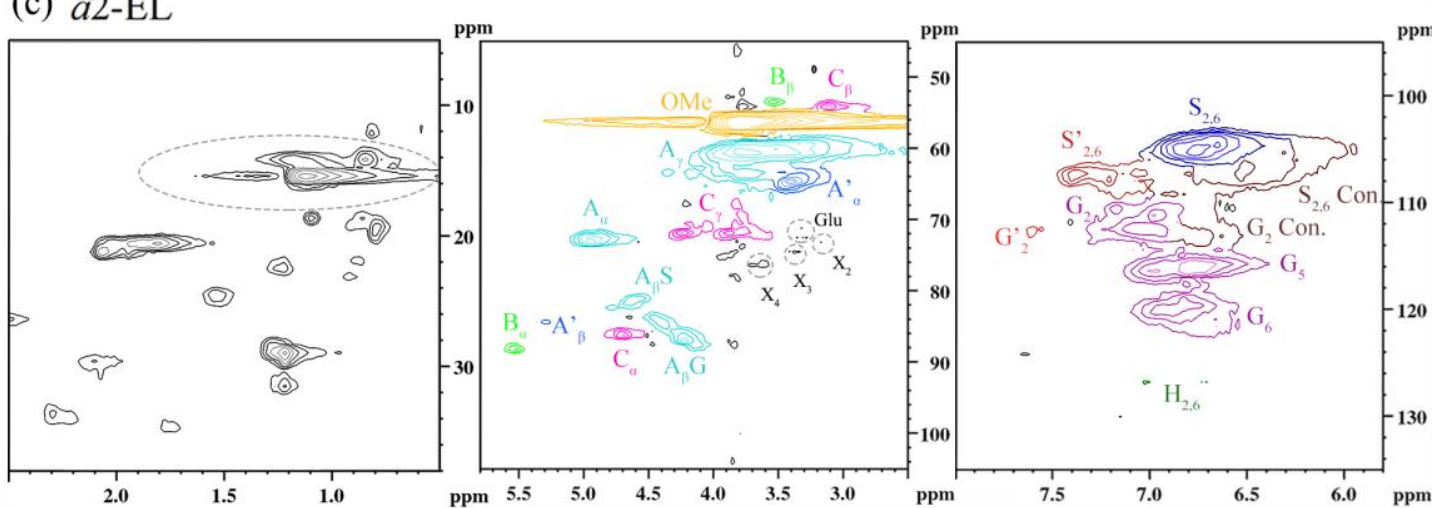

(d) $a 2-\mathrm{AL}$
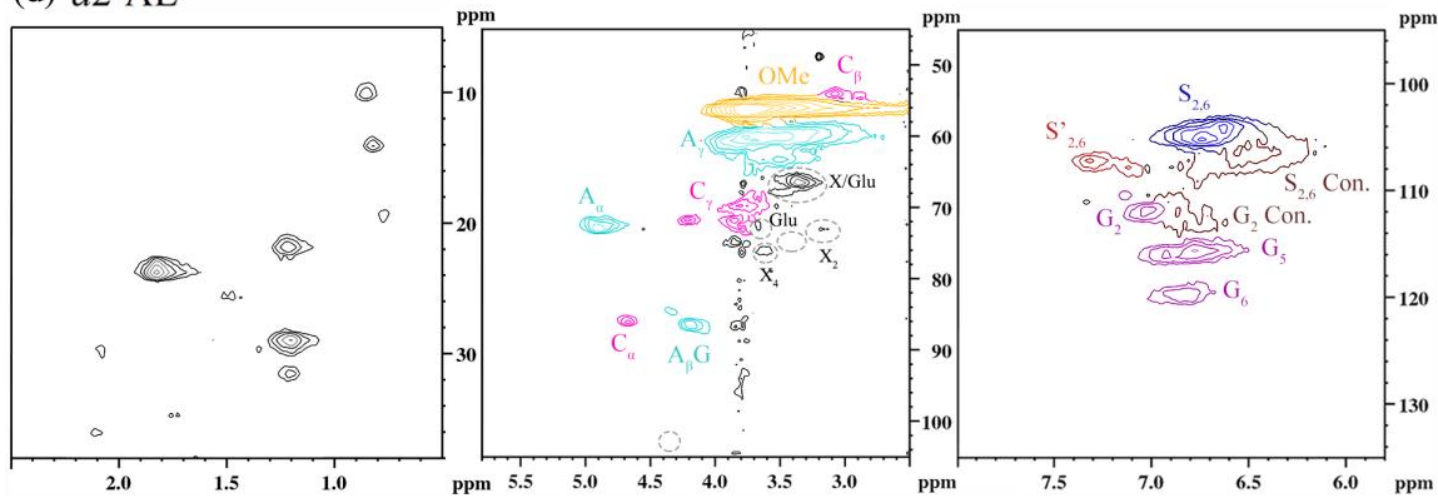

Figure 3. The HSQC NMR spectra for (a) $a 1$-EL, (b) $a 1-\mathrm{AL}$, (c) $a 2-\mathrm{EL}$ and (d) $a 2-\mathrm{AL}$ and three main regions for each lignin. 

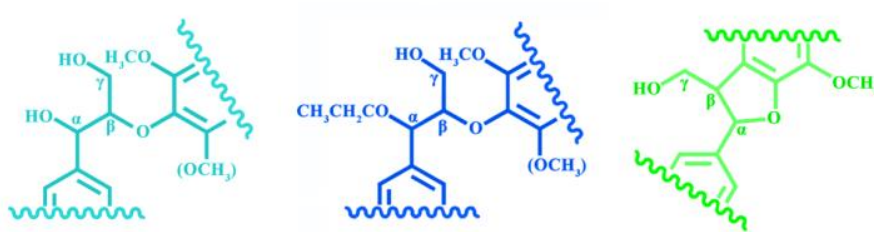

A

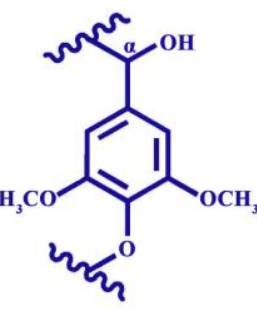

$\mathbf{S}$

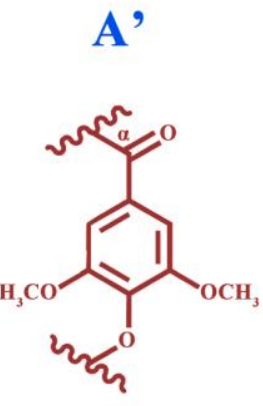

$S^{\prime}$
B

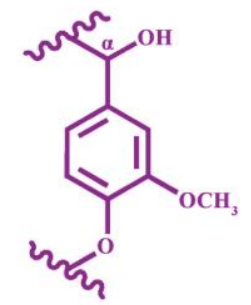

G

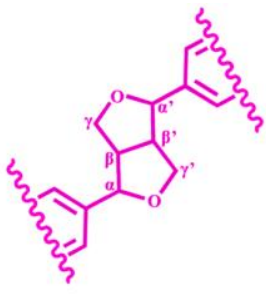

C

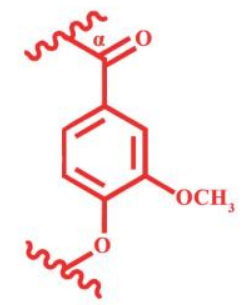

G'

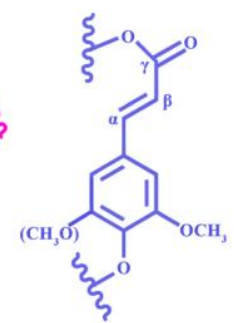

FA

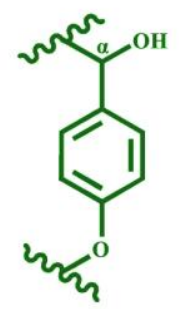

H

Figure 4. The chemical structure for main linkages and unites in lignin fraction. 


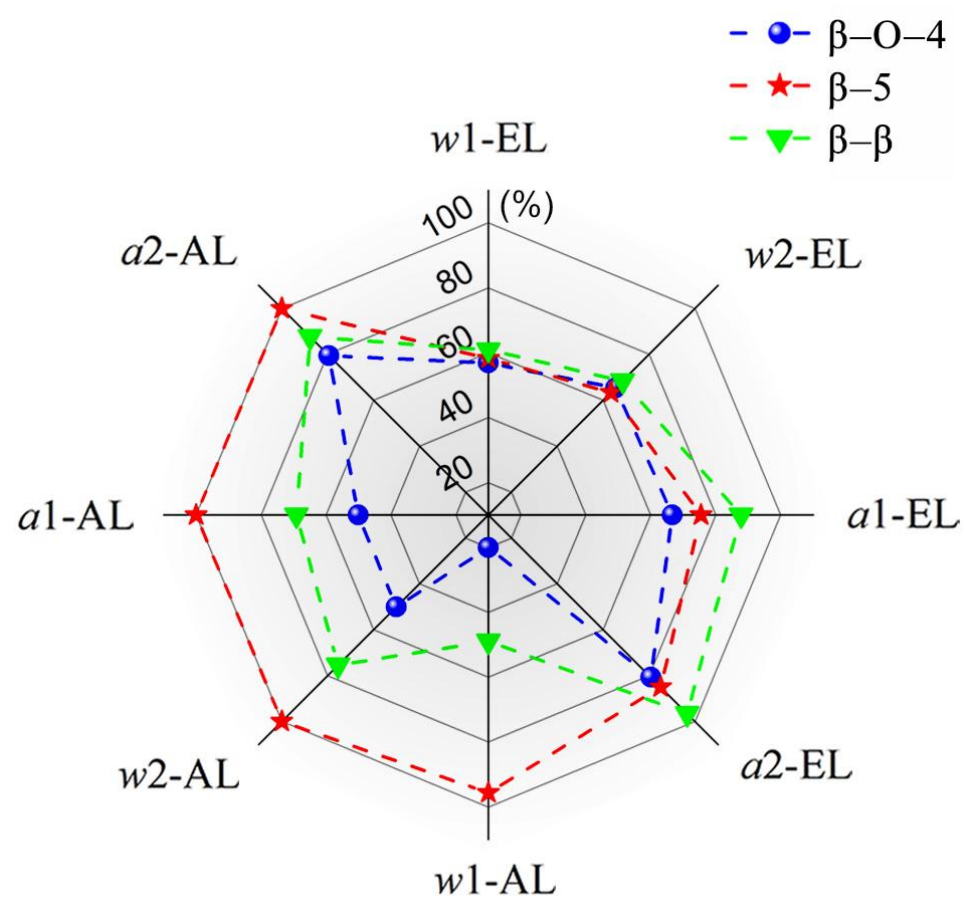

Figure 5. Change ratios of $\beta-\mathrm{O}-4, \beta-5$ and $\beta-\beta$ linkages for different lignin samples.

Change ratio $(\%)=\left[\left(\right.\right.$ value $_{\mathrm{MWL}}-$-value $\left._{\text {sample }}\right) /$ value $\left._{\mathrm{MWL}}\right] \times 100 \%$ 


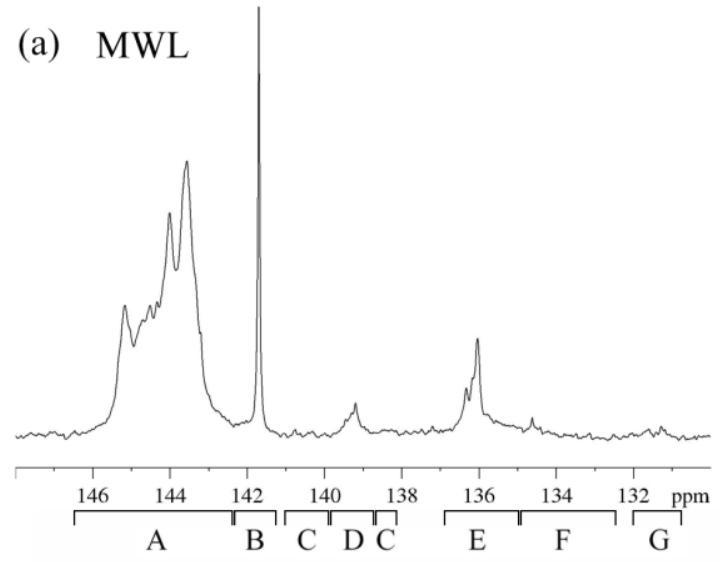
A: aliphatic $-\mathrm{OH}$ groups;
B: Internal standard;
$\mathrm{C}$ : condensed phenolic $-\mathrm{OH}$ groups;
D: syringyl $-\mathrm{OH}$ groups;
E: guiacyl -OH groups;
F: p-hydroxy -OH groups;
G: carboxyl groups $(-\mathrm{COOH})$
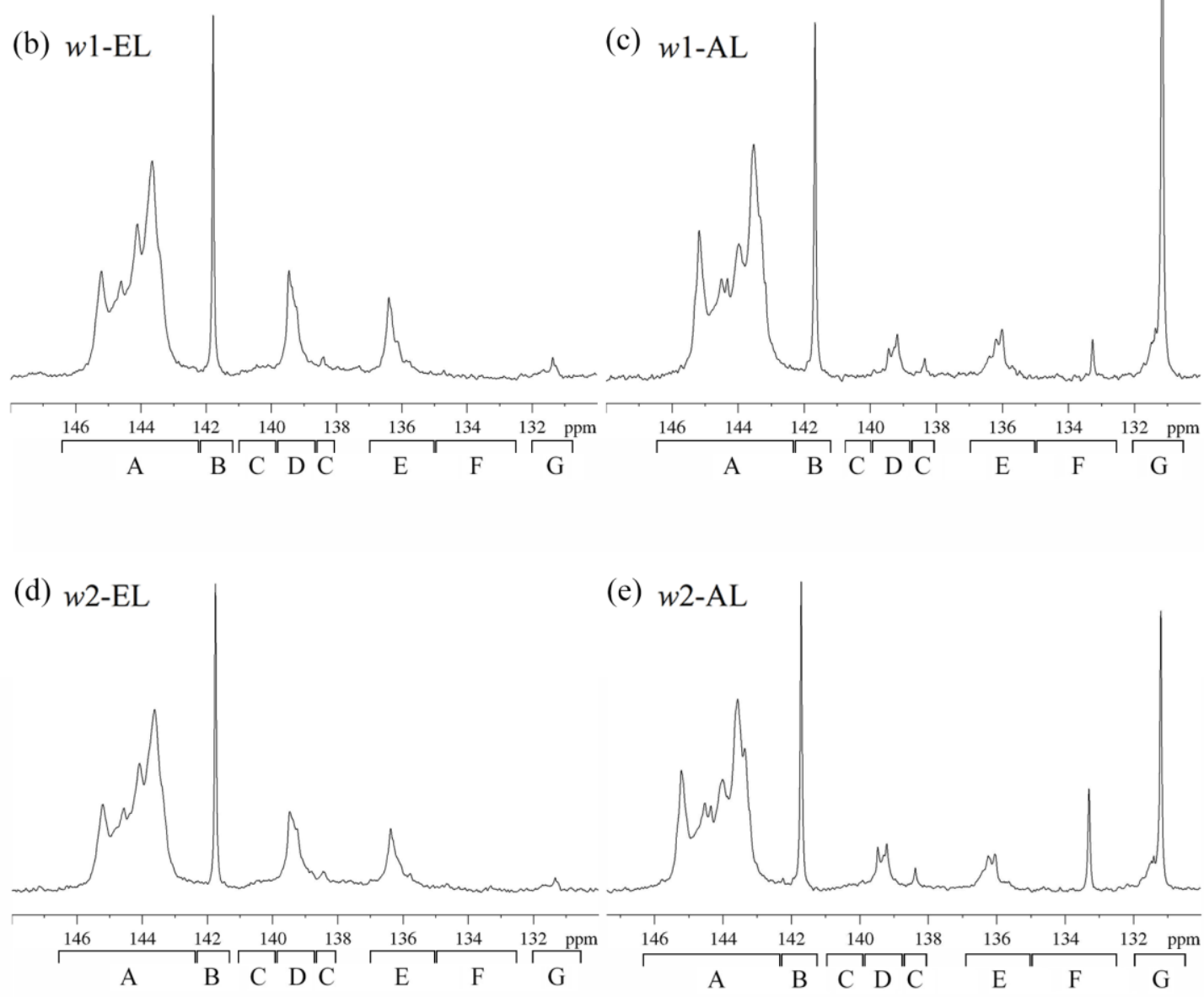

Figure $6 .{ }^{31} \mathrm{P}$ NMR spectra for (a) MWL, (b) $w 1$-EL, (c) $w 1-\mathrm{AL}$, (d) $w 2-\mathrm{EL}$ and (e)w2-AL and the assignments for different hydroxyl groups in lignin structure. 


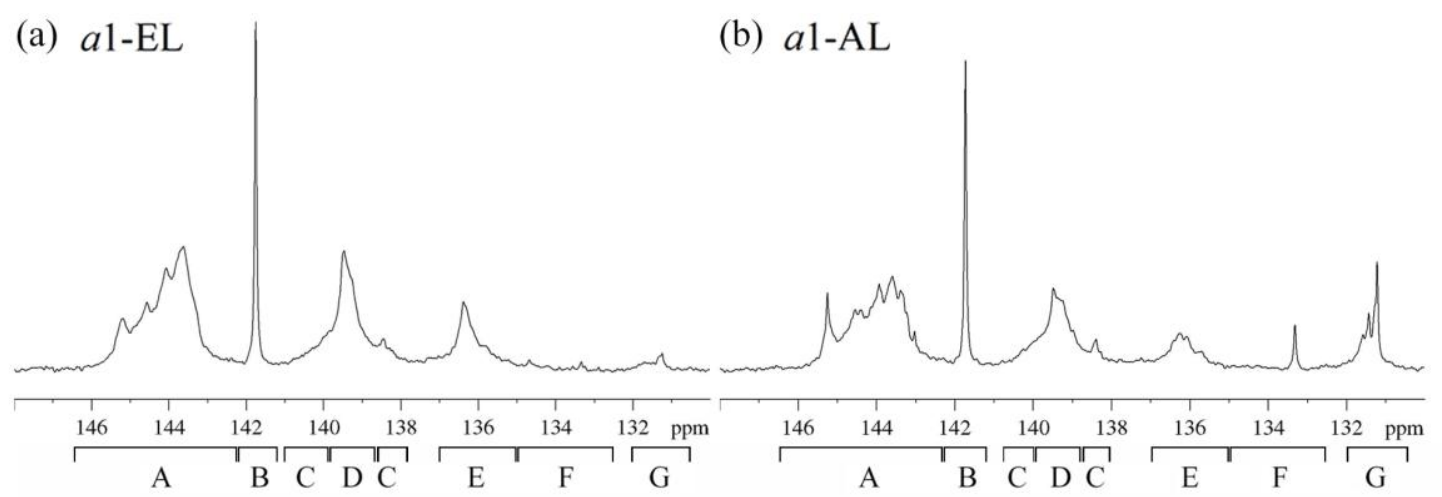

(c) $a 2$-EL

(d) $a 2-\mathrm{AL}$

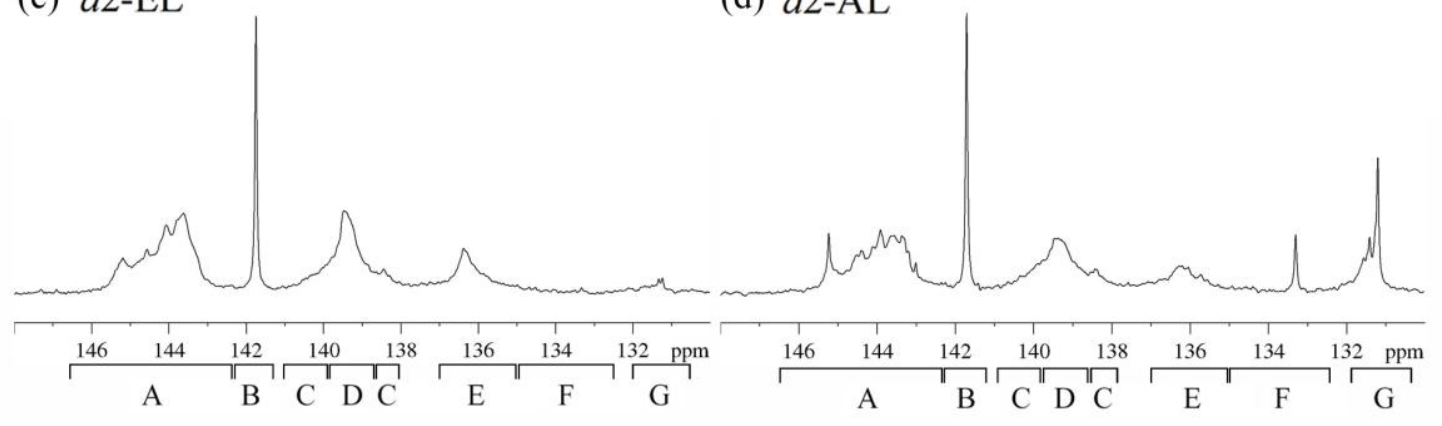

Figure $7 .{ }^{31} \mathrm{P}$ NMR spectra for (a) $a 1-\mathrm{EL}$, (b) $a 1-\mathrm{AL}$, (c) $a 2-\mathrm{EL}$ and (d) $a 2-\mathrm{AL}$. 


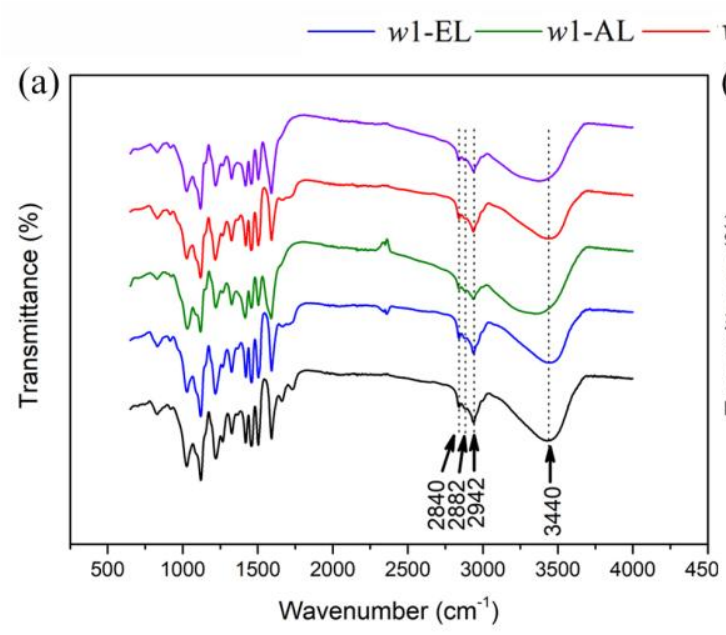

$w 2-\mathrm{EL}-w 2-\mathrm{AL}-\mathrm{MWL}$
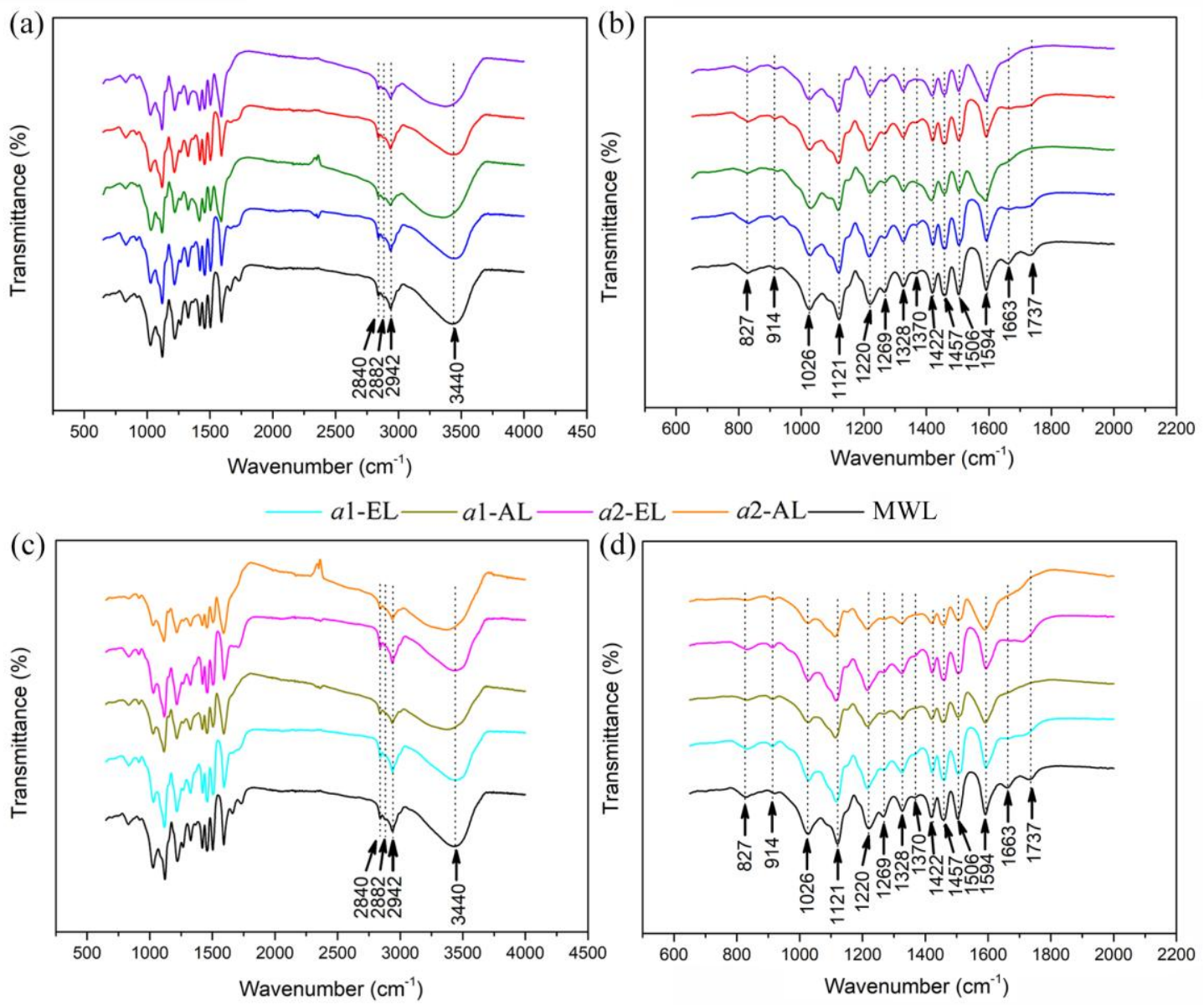

$a 2-\mathrm{EL} \longrightarrow a 2-\mathrm{AL} \longrightarrow \mathrm{MWL}$

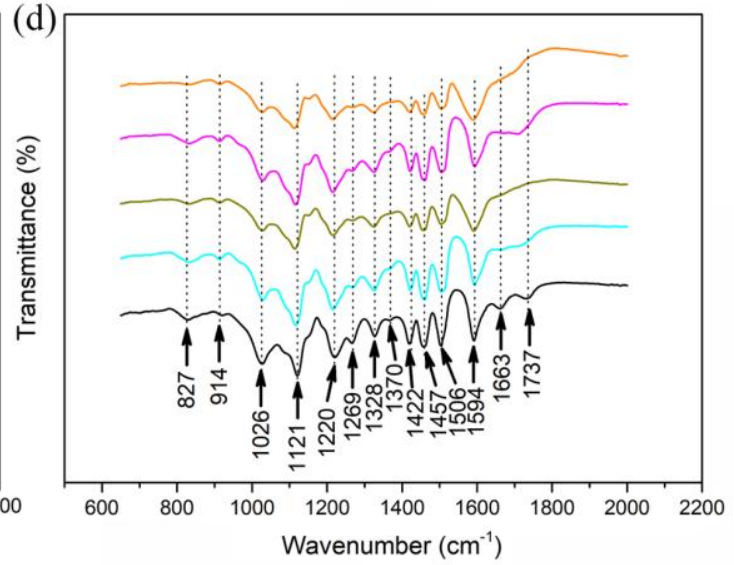

Figure 8. FTIR spectra for different lignin samples compared with MWL. (a)

$w$-lignins within $500 \sim 4000 \mathrm{~cm}^{-1}$, (b) $w$-lignins within $600 \sim 2000 \mathrm{~cm}^{-1}$, (c) $a$-lignins within $500 \sim 4000 \mathrm{~cm}^{-1}$ and (d) $a$-lignins within $600 \sim 2000 \mathrm{~cm}^{-1}$. 

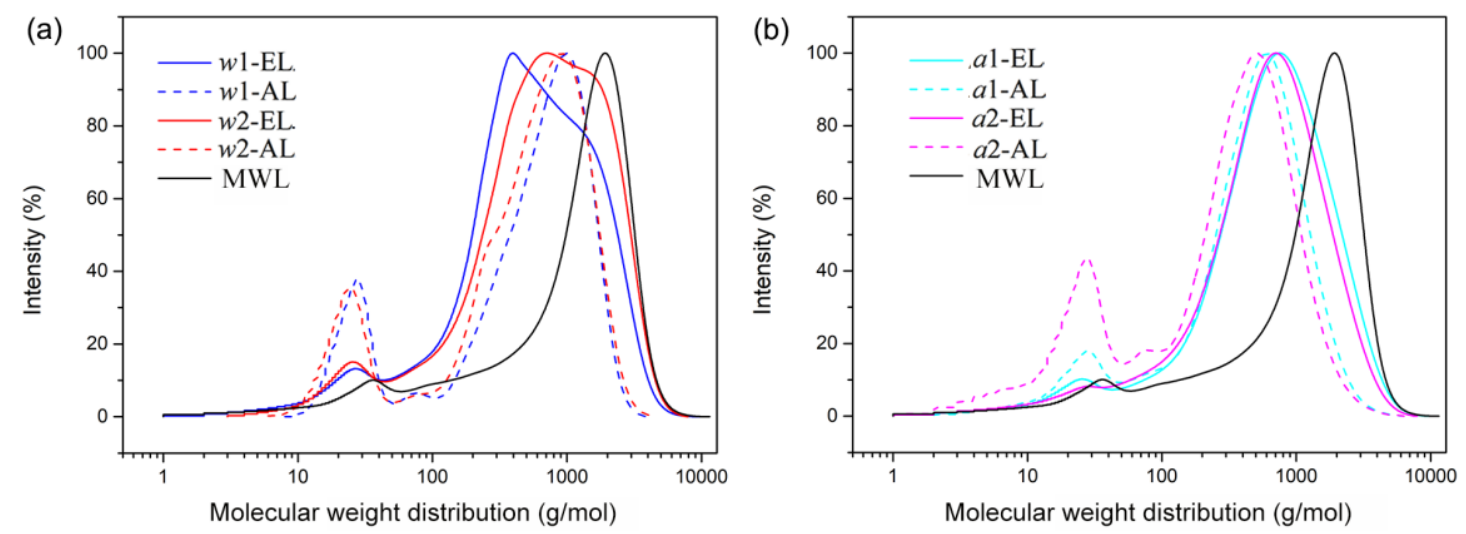

Figure 9. Molecular distribution chromatograms for different lignin samples compared with MWL. (a) $w$-lignins and (b) $a$-lignins. 


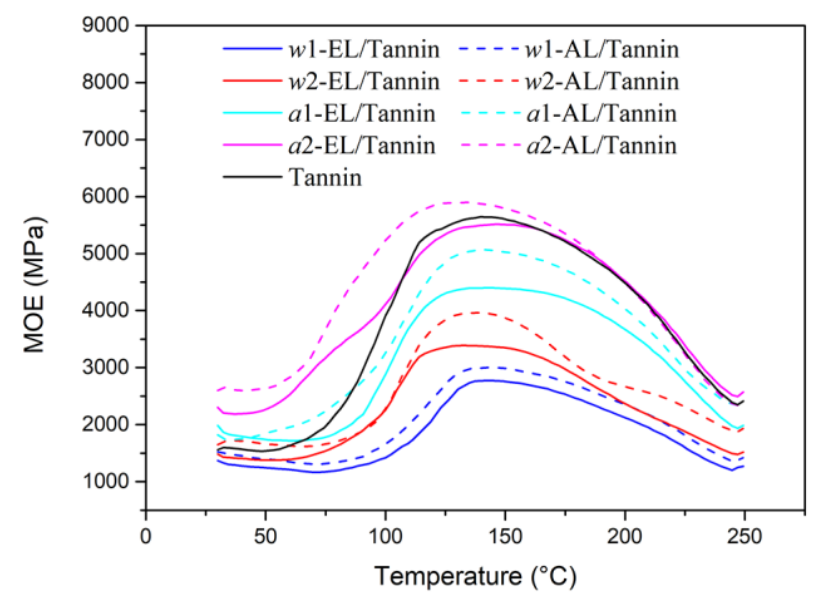

Figure 10. TMA spectra for the wood-joints with glyoxalated ELs/Tannin and glyoxalated ALs/Tannin resins. 
Table 1. Chemical compositions of SE-treated beech sawdust and their residues after lignin recovery.

\begin{tabular}{|c|c|c|c|c|c|c|c|c|c|}
\hline \multirow{3}{*}{$\begin{array}{c}\text { Composition } \\
(\%)\end{array}$} & \multicolumn{8}{|c|}{ SE-treated biomass } & Untreated \\
\hline & \multicolumn{4}{|c|}{ Water impregnation } & \multicolumn{4}{|c|}{ Acidic impregnation } & \\
\hline & \multicolumn{2}{|c|}{$w 1$} & \multicolumn{2}{|c|}{$w 2$} & \multicolumn{2}{|c|}{$a 1$} & \multicolumn{2}{|c|}{$a 2$} & l \\
\hline Lignin & \multicolumn{2}{|c|}{26.20} & \multicolumn{2}{|c|}{24.83} & \multicolumn{2}{|c|}{31.48} & \multicolumn{2}{|c|}{34.35} & 23.98 \\
\hline Cellulose & \multicolumn{2}{|c|}{42.93} & \multicolumn{2}{|c|}{42.40} & \multicolumn{2}{|c|}{52.54} & \multicolumn{2}{|c|}{48.74} & 40.73 \\
\hline $\begin{array}{l}\text { Hemi- } \\
\text { cellulose }\end{array}$ & \multicolumn{2}{|c|}{24.37} & \multicolumn{2}{|c|}{19.97} & \multicolumn{2}{|c|}{9.08} & \multicolumn{2}{|c|}{8.56} & 24.87 \\
\hline \multicolumn{10}{|c|}{ Residues after lignin recovery } \\
\hline & $w 1-\mathrm{E}$ & $w 1-\mathrm{A}$ & $w 2-\mathrm{E}$ & $w 2-\mathrm{A}$ & $a 1-\mathrm{E}$ & $a 1-\mathrm{A}$ & $a 2-\mathrm{E}$ & $a 2-\mathrm{A}$ & \\
\hline Lignin & 15.50 & 24.26 & 15.94 & 20.07 & 16.15 & 22.93 & 15.22 & 18.87 & \\
\hline Cellulose & 60.73 & 44.68 & 62.53 & 53.41 & 74.81 & 60.00 & 68.89 & 65.66 & \\
\hline $\begin{array}{l}\text { Hemi- } \\
\text { cellulose }\end{array}$ & 19.60 & 21.82 & 19.34 & 17.80 & 8.65 & 8.79 & 7.09 & 8.09 & \\
\hline
\end{tabular}


Table 2. Lignin yield and carbohydrate compositions of the lignin fraction

\begin{tabular}{ccccc|cccc}
\hline & \multicolumn{3}{c}{ Water impregnation } & \multicolumn{3}{c}{ Acidic impregnation } \\
\cline { 2 - 9 } & $w 1-\mathrm{EL}$ & $w 1-\mathrm{AL}$ & $w 2-\mathrm{EL}$ & $w 2-\mathrm{AL}$ & $a 1-\mathrm{EL}$ & $a 1-\mathrm{AL}$ & $a 2-\mathrm{EL}$ & $a 2-\mathrm{AL}$ \\
\hline Yield (\%) & 5.32 & 5.35 & 7.96 & 8.28 & 8.22 & 10.10 & 14.75 & 16.14 \\
Compositions (\%) & & & & & & & & \\
AIL & 96.23 & 97.36 & 97.27 & 96.89 & 98.18 & 96.15 & 99.07 & 95.45 \\
Glucose & 0.15 & 0.20 & 0.16 & 0.21 & 0.12 & 0.50 & 0.17 & 0.52 \\
Xylose & 0.94 & 1.61 & 0.63 & 1.56 & 0.62 & 0.56 & 0.69 & 0.61 \\
Arabinose & 0.04 & 0.18 & 0.02 & 0.11 & $/$ & 0.03 & 0.02 & 0.04 \\
Galactose & 0.02 & 0.04 & 0.02 & 0.03 & 0.01 & 0.01 & 0.01 & 0.02 \\
Rhamnose & $/$ & 0.11 & $/$ & 0.06 & 0.02 & 0.03 & 0.02 & 0.05 \\
acid galacturonic & $/$ & 0.14 & $/$ & 0.11 & $/$ & 0.12 & $/$ & 0.11 \\
Total & 1.14 & 2.28 & 0.84 & 2.08 & 0.77 & 1.26 & 0.92 & 1.35 \\
\hline
\end{tabular}

*Yield was calculated based on wood biomass. 
Table 3. Assignments of main lignin $13 \mathrm{C} / 1 \mathrm{H}$ cross-signals in HSQC NMR spectra.

\begin{tabular}{|c|c|c|}
\hline Unite & $\delta \mathrm{C} / \delta \mathrm{H}(\mathrm{ppm})$ & Assignments \\
\hline $\mathrm{B}_{\beta}$ & $53.70 / 3.53$ & $\mathrm{C}_{\beta} / \mathrm{H}_{\beta}$ in resinol substructure $(\mathrm{B})$ \\
\hline $\mathrm{C}_{\beta}$ & $54.35 / 3.04$ & $\mathrm{C}_{\beta} / \mathrm{H}_{\beta}$ in phenyl coumaran substructure $(\mathrm{C})$ \\
\hline $\mathrm{OMe}$ & $56.61 / 3.58$ & $\mathrm{CH}$ in methoxyl group \\
\hline $\mathrm{A}_{\gamma}$ & $59.19 / 3.57$ & $\mathrm{C}_{\gamma} / \mathrm{H}_{\gamma}$ in $\beta-\mathrm{O}-4$ linkage (A) \\
\hline $\mathrm{C}_{\gamma}$ & $71.13-71.77 / 3.91-4.22$ & $\mathrm{C}_{\gamma} / \mathrm{H}_{\gamma}$ in phenyl coumaran substructure $(\mathrm{C})$ \\
\hline $\mathrm{A}_{\alpha}^{\prime}$ & $64.67 / 3.36$ & Acetyl $_{\alpha}$ in $\beta-\mathrm{O}-4$ linkage \\
\hline $\mathrm{A}_{\alpha}$ & $72.10 / 4.78$ & $\mathrm{C}_{\alpha} / \mathrm{H}_{\alpha}$ in $\beta-\mathrm{O}-4$ linkage $(\mathrm{A})$ \\
\hline $\mathrm{A}_{\alpha}-O E t\left(\mathrm{~A}_{\beta} \mathrm{G}\right)$ & $81.13 / 4.59$ & $\mathrm{C}_{\beta} / \mathrm{H}_{\beta}$ in $\beta-\mathrm{O}-4$ linked to guaiacyl units (A) \\
\hline $\mathrm{A}_{\beta}\left(\mathrm{A}_{\beta} \mathrm{S}\right)$ & $84.36-86.29 / 4.14-4.34$ & $\mathrm{C}_{\beta} / \mathrm{H}_{\beta}$ in $\beta-\mathrm{O}-4$ linked to syringyl units (A) \\
\hline $\mathrm{B}_{\alpha}$ & $87.59 / 5.53$ & $\mathrm{C}_{\alpha} / \mathrm{H}_{\alpha}$ in resinol substructure $(\mathrm{B})$ \\
\hline $\mathrm{A}_{\beta}^{\prime}$ & $84.04 / 5.28$ & $\mathrm{~A}^{\mathrm{ox}} \beta$ \\
\hline $\mathrm{C}_{\alpha}$ & $85.33 / 4.67$ & $\mathrm{C}_{\alpha} / \mathrm{H}_{\alpha}$ in phenyl coumaran substructure (C) \\
\hline $\mathrm{S}_{2,6}$ & $104.85 / 6.65$ & $\mathrm{C}_{2,6} / \mathrm{H}_{2,6}$ in syringyle units $(\mathrm{S})$ \\
\hline $\mathrm{S}_{2,6}$ Con. & $107.46 / 6.43$ & $\mathrm{C}_{2,6} / \mathrm{H}_{2,6}$ condensed in syringyl units $(\mathrm{S})$ \\
\hline $\mathrm{S}_{2,6}$ & $107.27 / 7.27$ & $\mathrm{C}_{2,6} / \mathrm{H}_{2,6}$ in oxydised syringyl units ( $\left.\mathrm{S}^{\prime}\right)$ \\
\hline $\mathrm{G}_{2}$ & $111.46 / 7.02$ & $\mathrm{C}_{2} / \mathrm{H}_{2}$ in guaiacyl units $(\mathrm{G})$ \\
\hline $\mathrm{G}_{2}$ Con. & $112.48 / 6.78$ & $\mathrm{C}_{2} / \mathrm{H}_{2}$ condensed in guaiacyl units \\
\hline $\mathrm{G}_{2}^{\prime}$ & $112.45 / 7.60$ & $\mathrm{C}_{2} / \mathrm{H}_{2}$ in oxydised guaiacyl units $\left(\mathrm{G}^{\prime}\right)$ \\
\hline $\mathrm{G}_{5}$ & $115.98 / 6.78$ & $\mathrm{C}_{5} / \mathrm{H}_{5}$ in guaiacyl units $(\mathrm{G})$ \\
\hline $\mathrm{G}_{6}$ & $120.18 / 6.84$ & $\mathrm{C}_{6} / \mathrm{H}_{6}$ in guaiacyl units $(\mathrm{G})$ \\
\hline $\mathrm{FA}_{2}$ & $113.72 / 7.30$ & $\mathrm{C}_{2} / \mathrm{H}_{2}$ in Ferulate $(\mathrm{FA})$ \\
\hline $\mathrm{FA}_{6}$ & $119.21 / 7.35$ & $\mathrm{C}_{6} / \mathrm{H}_{6}$ in ferulate $(\mathrm{FA})$ \\
\hline $\mathrm{H}_{2,6}$ & $126.63 / 6.74-7.01$ & $\mathrm{C}_{2,6} / \mathrm{H}_{2,6}$ in p-hydroxyphenyl $(\mathrm{H})$ \\
\hline \multicolumn{3}{|l|}{ Carbohydrates } \\
\hline $\mathrm{X}_{2}$ & $72.74 / 3.17$ & $\mathrm{C}_{2} / \mathrm{H}_{2}$ in $\beta$-D-xylopyranoside \\
\hline $\mathrm{X}_{3}$ & $74.35 / 3.40$ & $\mathrm{C}_{2} / \mathrm{H}_{2}$ in $\beta$-D-xylopyranoside \\
\hline $\mathrm{X}_{4}$ & $75.65 / 3.59$ & $\mathrm{C}_{2} / \mathrm{H}_{2}$ in $\beta$-D-xylopyranoside \\
\hline $\mathrm{X}_{1}$ & $102.11 / 4.35$ & $\mathrm{C}_{1} / \mathrm{H}_{1}$ in $\beta-\mathrm{D}-\mathrm{xylopyranoside}$ \\
\hline Glu & $72.74 / 3.64$ & $\mathrm{C}_{2} / \mathrm{H}_{2}$ in $4-O-\mathrm{Me}-\alpha-\mathrm{D}-$ glucuronic acid \\
\hline X/Glu & $66.29-67.90 / 3.33-3.42$ & $\beta-\mathrm{D}-\mathrm{xylopyranoside} / \beta-\mathrm{D}$-glucuronic acid \\
\hline
\end{tabular}


Table 4. Quantification of lignin side chains and aromatic regions.

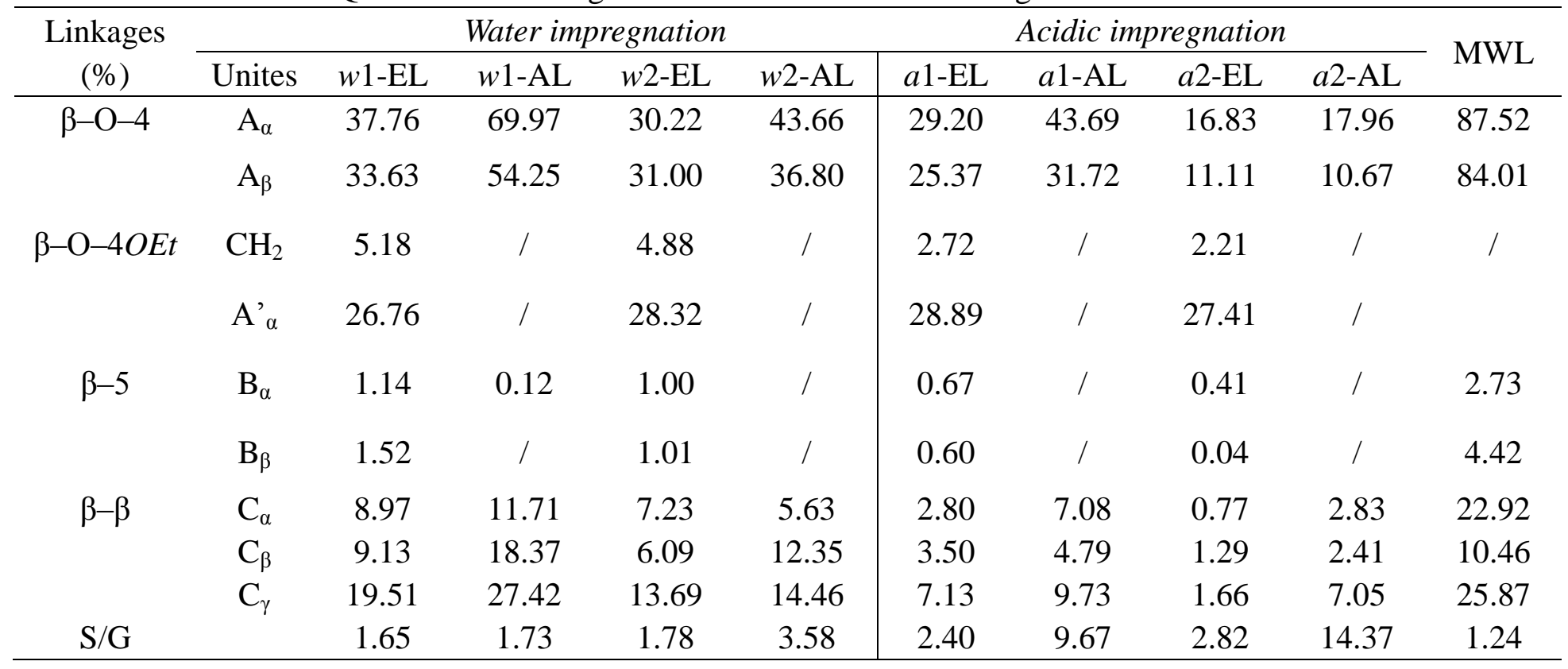


Table 5. The contents of lignin hydroxyl groups measured by ${ }^{31} \mathrm{P}$ NMR.

\begin{tabular}{|c|c|c|c|c|c|c|c|c|c|}
\hline \multirow{2}{*}{ Content $(\mathrm{mmol} / \mathrm{g})$} & \multicolumn{4}{|c|}{ Water impregnation } & \multicolumn{4}{|c|}{ Acidic impregnation } & \multirow{2}{*}{ MWL } \\
\hline & $w 1-\mathrm{EL}$ & $w 1-\mathrm{AL}$ & $w 2-\mathrm{EL}$ & $w 2-\mathrm{AL}$ & $a 1-\mathrm{EL}$ & $a 1-\mathrm{AL}$ & $a 2-\mathrm{EL}$ & $a 2-\mathrm{AL}$ & \\
\hline $\begin{array}{c}\text { Aliphatic }(\mathrm{R}) \\
-\mathrm{OH}\end{array}$ & 2.32 & 2.16 & 2.20 & 2.01 & 1.44 & 1.34 & 1.19 & 1.02 & 2.52 \\
\hline Condensed $\mathrm{PhOH}$ & 0.16 & 0.05 & 0.15 & 0.07 & 0.35 & 0.24 & 0.28 & 0.27 & 0.03 \\
\hline Syringyl -OH & 0.40 & 0.13 & 0.40 & 0.20 & 0.59 & 0.50 & 0.59 & 0.45 & 0.09 \\
\hline Guiacyl -OH & 0.34 & 0.19 & 0.32 & 0.18 & 0.39 & 0.28 & 0.37 & 0.28 & 0.33 \\
\hline p-Hydroxy -OH & I & 0.06 & 0.01 & 0.07 & 0.02 & 0.06 & 0.03 & 0.11 & 0.03 \\
\hline Total phOH & 0.91 & 0.43 & 0.87 & 0.53 & 1.35 & 1.08 & 1.28 & 1.11 & 0.48 \\
\hline$-\mathrm{COOH}$ & 0.06 & 0.60 & 0.03 & 0.36 & 0.05 & 0.28 & 0.06 & 0.35 & 0.03 \\
\hline $\mathrm{PhOH} / \mathrm{ROH}$ & 0.39 & 0.20 & 0.40 & 0.26 & 0.94 & 0.81 & 1.07 & 1.09 & 0.19 \\
\hline
\end{tabular}


Table 6. FTIR spectra assignments for lignin samples.

\begin{tabular}{|c|c|c|}
\hline Band $\left(\mathrm{cm}^{-1}\right)$ & Vibration & Assignment \\
\hline 3440 & $\mathrm{O}-\mathrm{H}$, stretching vibration & Phenolic $\mathrm{OH}+$ aliphatic $\mathrm{OH}$ \\
\hline 2942 & $\mathrm{C}-\mathrm{H}$, stretching vibration & $\mathrm{CH}_{3}+\mathrm{CH}_{2}$ \\
\hline 2882 & $\mathrm{C}-\mathrm{H}$, stretching vibration & $\mathrm{CH}_{3}+\mathrm{CH}_{2}$ \\
\hline 2840 & $\mathrm{C}-\mathrm{H}$, stretching vibration & $\mathrm{OCH}_{3}$ \\
\hline 1737 & $\mathrm{C}=\mathrm{O}$, stretching vibration & Unconjugated $\mathrm{C}=\mathrm{O}$ \\
\hline 1663 & $\mathrm{C}=\mathrm{O}$, stretching vibration & conjugated $\mathrm{C}=\mathrm{O}$ \\
\hline 1594 & $\mathrm{C}-\mathrm{C}$, stretching vibration & Aromatic skeleton \\
\hline 1506 & $\mathrm{C}-\mathrm{C}$, stretching vibration & Aromatic skeleton \\
\hline 1457 & $\mathrm{C}-\mathrm{H}$ & $\mathrm{CH}_{3}+\mathrm{CH}_{2}$ \\
\hline 1422 & $\mathrm{C}-\mathrm{C}$, stretching vibration & Aromatic skeleton \\
\hline 1370 & $\mathrm{O}-\mathrm{H}$, in-plane deformation vibration & Phenolic $\mathrm{OH}$ \\
\hline 1328 & $\mathrm{C}-\mathrm{O}$, stretching vibration & S \\
\hline 1269 & $\mathrm{C}-\mathrm{O}$, stretching vibration & G \\
\hline 1220 & $\mathrm{C}-\mathrm{O}(\mathrm{H})+\mathrm{C}-\mathrm{O}(\mathrm{Ar})$, stretching vibration & Phenolic $\mathrm{OH}+$ ether \\
\hline 1121 & $\mathrm{~A}_{\mathrm{r}} \mathrm{C}-\mathrm{H}$, in-plane deformation vibration & $\mathrm{G}$ \\
\hline 1026 & $\mathrm{C}-\mathrm{O}(\mathrm{H})+\mathrm{C}-\mathrm{O}(\mathrm{C})$, stretching vibration & $1^{\text {st }}$ order aliphatic $\mathrm{OH}+$ ether \\
\hline 914 & $\mathrm{~A}_{\mathrm{r}} \mathrm{C}-\mathrm{H}$, out-of-plane deformation vibration & $\mathrm{G}$ \\
\hline 827 & $\mathrm{~A}_{\mathrm{r}} \mathrm{C}-\mathrm{H}$, out-of-plane deformation vibration & $\mathrm{S}$ \\
\hline
\end{tabular}


Table 7. Weight-average molecular weight, number-average molecular weight and Mw/Mn of lignins.

\begin{tabular}{ccccc|ccccc}
\hline & \multicolumn{3}{c}{ Water impregnation } & \multicolumn{5}{c}{ Acidic impregnation } & \multirow{2}{*}{ MWL } \\
\cline { 2 - 8 } & $w 1-\mathrm{EL}$ & $w 1-\mathrm{AL}$ & $w 2-\mathrm{EL}$ & $w 2-\mathrm{AL}$ & $a 1-\mathrm{EL}$ & a1-AL & a2-EL & a2-AL & \\
\hline $\mathrm{M}_{\mathrm{w}}$ & 891 & 868 & 1071 & 822 & 995 & 677 & 956 & 614 & 1926 \\
$\mathrm{M}_{\mathrm{n}}$ & 363 & 565 & 423 & 459 & 425 & 356 & 394 & 382 & 1265 \\
$\mathrm{M}_{\mathrm{w}} / \mathrm{M}_{\mathrm{n}}$ & 2.45 & 1.54 & 2.53 & 1.79 & 2.34 & 1.90 & 2.43 & 1.61 & 1.52 \\
\hline
\end{tabular}

